\title{
Interferon-induced transmembrane protein 1 (IFITM1) overexpression enhances the aggressive phenotype of SUM149 inflammatory breast cancer cells in a signal transducer and activator of transcription 2 (STAT2)-dependent manner
}

\author{
Joshua Ogony ${ }^{1}$, Hye Joung Choi ${ }^{1}$, Asona Lui ${ }^{1,2}$, Massimo Cristofanilli ${ }^{3}$ and Joan Lewis-Wambi ${ }^{1 *}$
}

\begin{abstract}
Background: Inflammatory breast cancer (IBC) is a very aggressive and lethal subtype of breast cancer that accounts for about $4 \%$ of all breast cancers diagnosed in the United States. Despite the efforts of several investigators to identify the molecular factors driving the aggressive phenotype of IBC, a great deal is still unknown about the molecular underpinnings of the disease. In the present study, we investigated the role of interferon-induced transmembrane protein 1 (IFITM1), a well-known interferon-stimulated gene (ISG), in promoting the aggressiveness of SUM149 IBC cells.

Methods: Western blot and real-time polymerase chain reaction analyses were performed to assess the protein and messenger RNA (mRNA) levels of IFITM1 and other ISGs in three IBC cell lines: SUM149, MDA-IBC-3, and SUM190. IFITM1 expression and cellular localization were assessed by using immunofluorescence, while the tumorigenic potential was assessed by performing cell migration, invasion, and colony formation assays. Small interfering RNA and short hairpin RNA knockdowns, enzyme-linked immunosorbent assays, and luciferase assays were performed to determine the functional significance of IFITM1 and signal transducers and activators of transcription 1 and 2 (STAT1/2) in SUM149 cells.

Results: We found that IFITM1 was constitutively overexpressed at the mRNA and protein levels in triple-negative SUM149 IBC cells, but that it was not expressed in SUM190 and MDA-IBC-3 IBC cells, and that suppression of IFITM1 or blockade of the IFNa signaling pathway significantly reduced the aggressive phenotype of SUM149 cells. Additionally, we found that knockdown of STAT2 abolished IFITM1 expression and IFITM1 promoter activity in SUM149 cells and that loss of STAT2 significantly inhibited the ability of SUM149 cells to proliferate, migrate, invade, and form 2-D colonies. Notably, we found that STAT2-mediated activation of IFITM1 was particularly dependent on the chromatin remodeler brahma-related gene 1 (BRG1), which was significantly elevated in SUM149 cells compared with SUM190 and MDA-IBC-3 cells.

(Continued on next page)
\end{abstract}

\footnotetext{
* Correspondence: jlewis-wambi@kumc.edu

${ }^{1}$ Department of Cancer Biology, University of Kansas Medical Center, Kansas

City, KS, USA

Full list of author information is available at the end of the article
} 
(Continued from previous page)

Conclusions: These findings indicate that overexpression of IFITM1 enhances the aggressive phenotype of triple-negative SUM149 IBC cells and that this effect is dependent on STAT2/BRG1 interaction. Further studies are necessary to explore the potential of IFITM1 as a novel therapeutic target and prognostic marker for some subtypes of IBCS.

Keywords: Inflammatory breast cancer, IFITM1, JAK/STAT signaling, Interferon-stimulated genes, BRG1

\section{Background}

Inflammatory breast cancer (IBC) is one of the most aggressive and lethal subtypes of human breast cancer, accounting for about $4 \%$ of all breast cancer cases diagnosed in the United States. A recent study published by Fouad et al. [1] showed that the 5-year overall survival for patients diagnosed with stage IV IBC is significantly lower than that of patients diagnosed with stage IV non-IBC, emphasizing the lethality of IBC [2-5]. In the last decade, remarkable progress has been made toward genomic profiling of IBC, leading to identification of molecular alterations commonly found in these tumors. The most notable alterations that have been reported include lack of estrogen and progesterone receptors (ER-/PR-); overexpression of epidermal growth factor receptor, ERBB2/human epidermal growth factor receptor 2 (HER2), E-cadherin, eIF4GI, chemokines, and chemokine receptors; dysfunction of mucin 1; high proliferation; tumor protein 53 mutations; and elevated angiogenesis [6]. Despite these efforts, however, there is still a great deal that is not known about the biology of IBC or the factors that drive its aggressive phenotype.

A recent study by the international IBC consortium reported that the interferon alpha (IFN $\alpha$ ) signaling pathway was significantly upregulated in IBC [7]. Interferons (IFNs) are cytokines that affect biological responses through the Janus kinase/signal transducer and activator of transcription (JAK-STAT) signaling pathway. This pathway involves IFNs, which, acting as ligands, bind their corresponding receptors [interferon (alpha, beta and omega) receptor (IFNAR)/interferon gamma receptor], resulting in the phosphorylation and activation of STAT1 and STAT2 and subsequent transcription of interferonstimulated genes (ISGs), which include STAT1, STAT2, phospholipid scramblase 1 (PLSCR1), interferon-induced transmembrane protein 1 (IFITM1), interferon-inducible protein 27 (IFI27), interferon-induced protein with tetratricopeptide repeats 1 (IFIT1), and many others [8]. The transcription of these ISGs requires the remodeling of their promoter regions to increase accessibility to transcription factors. Brahma-related gene 1 (BRG1), which is the adenosine triphosphate (ATP) subunit of the brahmaassociated factor (BAF) complex, is responsible for the remodeling of the promoter region of many ISGs and is recruited to its site of action by STAT2 [9]. Several studies have suggested that altered type I IFN $\alpha / \operatorname{IFN} \beta$ signaling, resulting in increased expression of ISGs, might play a role in tumorigenesis and contribute to poor patient prognosis [10-13]. Indeed, increased expression of IFITM1, a well-known ISG, has been shown to correlate with disease progression, resistance to endocrine therapy and chemotherapy, and worse overall prognosis in patients with gastrointestinal, colorectal, and breast cancers $[14,15]$.

IFITM1 is a member of the IFITM protein family whose expression is strongly induced by type I IFNs [16]. It was initially identified as a leukocyte antigen that is part of a membrane complex involved in the transduction of antiproliferative and homotypic cell adhesion signals in lymphocytes [17]. Most recently, however, there has been evidence to suggest that IFITM1 might also play a role in tumorigenesis. IFITM1 has been shown to be overexpressed in several types of cancers, including colorectal, gastrointestinal, head and neck, and breast cancers, and its overexpression positively correlates with tumor progression and increased invasiveness [14, 18-21]. We hypothesized that hyperactivation of the IFN $\alpha$ signaling pathway drives IFITM1 overexpression, which enhances the aggressive phenotype of IBC cells.

In this study, we measured IFITM1 expression in three IBC cell lines-SUM149, SUM190, and MDA-IBC3-and in a non-IBC breast cancer cell line, MCF-7. We found that IFITM1 was highly expressed in SUM149 cells, which are ER-/PR-/HER2-, but not expressed in HER2-overexpressing SUM190 and MDA-IBC-3 cells or $\mathrm{ER}+/ \mathrm{PR}+\mathrm{MCF}-7$ cells. We also found that IFITM1 overexpression promoted-whereas its knockdown inhibited-proliferation, migration, invasion, and tumorigenicity in SUM149 cells. Additionally, we determined that blockade of IFN $\alpha$ signaling using a neutralizing antibody against its receptor, IFNAR1/2, or knockdown of STAT2 and the chromatin remodeling protein BRG1, dramatically reduced IFITM1 expression and the tumorigenic potential of SUM149 cells. These findings suggest a critical role for IFN $\alpha$ signaling and STAT2-mediated activation of IFITM1 in promoting the aggressiveness of triple-negative SUM149 IBC cells; however, additional studies need to be performed in other triple-negative inflammatory breast cancer (TNIBC) cell lines as well as in IBC tumors to validate the biological and clinical significance of these findings in IBC. 


\section{Methods \\ Reagents}

Ham's F-12 $(1 \times)$ nutrient mixture (catalogue number 11765-054), RPMI 1640 medium (catalogue number 11875-093), fetal bovine serum (FBS; catalogue number 16000-044), antibiotic/antimycotic solution (containing $10,000 \mathrm{U} / \mathrm{ml}$ penicillin, $10 \mathrm{mg} / \mathrm{ml}$ streptomycin, and $25 \mu \mathrm{g} /$ ml Fungizone ${ }^{\circledast}$ ), minimum essential medium nonessential amino acids, L-glutamine, and TrypLE (containing trypsin and ethylenediaminetetraacetic acid) were obtained from Life Technologies (Grand Island, NY, USA). Insulin (bovine pancreas), anti- $\beta$-actin, and hydrocortisone were obtained from Sigma-Aldrich (St. Louis, MO, USA). Anti-IFITM1, anti-STAT1, anti-STAT2, anti-BRG1, anti-p-STAT2 (Tyr690), anti-interferon regulatory factor (IRF)-7, anti-IFNo, anti-p21, anti-cyclin D1, and anti-cyclin E antibodies were purchased from Santa Cruz Biotechnology (Santa Cruz, CA, USA), and rabbit polyclonal and mouse monoclonal secondary antibodies and anti-p-STAT1 (Tyr701) were purchased from Cell Signaling Technology (Danvers, MA, USA). IFITM1 promoter constructs were kindly provided by Dr. Yeon-Su Lee from the Cancer Genomics Branch, National Cancer Center, Goyang-si, South Korea.

\section{Cell lines and culture conditions}

Experiments were performed using the IBC cell lines SUM149, SUM190, and MDA-IBC-3 and a non-IBC breast cancer cell line, MCF-7. SUM149 and SUM190 cells were obtained from Dr. Massimo Cristofanilli (Northwestern University, Chicago, IL, USA), who purchased them from Asterand Bioscience (Detroit, MI, USA). MDA-IBC-3 cells were developed by Dr. Wendy Woodward (The University of Texas MD Anderson Cancer Center, Houston, TX, USA) and were provided to us by Dr. Massimo Cristofanilli (Northwestern University, Chicago IL). The IBC cells were maintained in Ham's F-12 nutrient mixture supplemented with $10 \% \mathrm{FBS}, 5 \mu \mathrm{g} / \mathrm{ml}$ insulin, $1 \mu \mathrm{g} / \mathrm{ml}$ hydrocortisone, and $100 \mathrm{U} / \mathrm{ml}$ antibiotic-antimycotic. The ER+, hormonedependent human breast cancer cell line MCF-7 was obtained from the American Type Culture Collection (Manassas, VA, USA) and was maintained in full serum medium composed of RPMI 1640 medium, 10 \% FBS, $2 \mathrm{mM}$ glutamine, penicillin at $100 \mathrm{U} / \mathrm{ml}$, streptomycin at $100 \mu \mathrm{g} / \mathrm{ml}, 1 \times$ nonessential amino acids (Life Technologies), and bovine insulin at $6 \mathrm{ng} / \mathrm{ml}$ (Sigma-Aldrich, St Louis, MO). The cells were passaged twice weekly, with media changed every other day, and they were cultured at $37{ }^{\circ} \mathrm{C}$ in a $5 \% \mathrm{CO}_{2}$ atmosphere. The cells were plated and incubated overnight for attachment before the treatment protocols were begun.

\section{Anchorage-independent growth}

Anchorage-independent growth was performed in soft agar for SUM149 and SUM190 cells. The experiments were performed in 6-well plates as per the protocol published by Debeb et al. [22]. Briefly, the base layer was made of $2 \mathrm{ml}$ of medium containing $1 \%$ FBS and $0.5 \%$ agarose (A9539-100G; Sigma-Aldrich). A quantity of $5 \times$ $10^{4}$ cells was layered onto the base in $2 \mathrm{ml}$ of medium containing $1 \%$ FBS and $0.35 \%$ agarose. The plates were briefly cooled at $4{ }^{\circ} \mathrm{C}$ so that agarose could solidify before the growth medium was added, and the plates were kept in the $37{ }^{\circ} \mathrm{C}$ incubator for 21 days. Images of the colonies were captured using the ChemiDoc ${ }^{\mathrm{TM}}$ XRS System equipped with Image Lab $^{\text {тм }}$ software (Bio-Rad Laboratories, Hercules, CA, USA), and using a phasecontrast microscope equipped with an Olympus camera (Olympus America, Center Valley, PA, USA).

\section{2-D colony formation}

SUM149 cells were plated at low density in 6-well plates and cultured for 7 days, with media changed every other day. At the end of the 7 days, the colonies were stained with $5 \%$ crystal violet for 5 minutes and then washed. The images of the colonies were captured using the ChemiDoc $^{\text {тм }}$ XRS System equipped with Image Lab ${ }^{\text {тм }}$ software.

\section{Wound-healing assay}

SUM149 and SUM190 cells were seeded at a density of $3.0 \times 10^{5}$ cells per well in 6-well culture plates overnight so that the cells would attach. A single wound was made on the plates for each cell line by scratching the attached cells using a 200- $\mu$ l sterile pipette tip. The plates were washed with complete medium to remove cellular debris from the scraped surface. The images of the cells were taken immediately and after 24, 48, and $72 \mathrm{~h}$ using a phase-contrast microscope.

\section{Cell invasion assay}

Cell invasion measurements were performed using the Chemicon 24-well QCM ECMatrix Cell Invasion Assay (ECM 554; EMD Millipore, Billerica, MA, USA) according to the manufacturer's protocol. Briefly, IBC cells $\left(1 \times 10^{5}\right)$ in $250 \mu \mathrm{l}$ of serum-free medium were added to each insert, and $500 \mu \mathrm{l}$ of media with or without a chemoattractant (10\% FBS) was added to the lower chamber. The plates were returned to the incubator at $37{ }^{\circ} \mathrm{C}$ in a $5 \% \mathrm{CO}_{2}$ atmosphere for $48 \mathrm{~h}$. The media with noninvading cells were removed from the inserts, and the inserts were placed in cell detachment medium and incubated for 30 minutes at $37{ }^{\circ} \mathrm{C}$ to dislodge the invaded cells. The invaded cells were lysed in the presence of Molecular Probes CyQUANT GR Dye (Life Technologies, Eugene, OR, USA) for 15 minutes at room temperature, and the fluorescence of 200- $\mu$ l aliquots in 96-well plates was measured using a fluorescence plate reader with a 480/520-nm filter set. For a second set of 
inserts, the migrated cells were stained with crystal violet and the images were captured with a phasecontrast microscope equipped with an Olympus camera.

\section{MTT assay}

Proliferation of IBC cells was determined by using a 3(4,5-dimethylthiazol-2-yl)-2,5-diphenyltetrazolium bromide (MTT) assay. SUM149 and SUM190 cells were seeded onto 24-well plates at a density of $2.5 \times 10^{4}$ cells per well in cell culture media and incubated overnight for attachment, followed by treatment protocols. A $50-\mu \mathrm{l}$ MTT solution $(5 \mathrm{mg} / \mathrm{ml})$ was added to each well at a final concentration of $500 \mu \mathrm{g} / \mathrm{ml}$, and the mixture was further incubated for $3 \mathrm{~h}$ at $37{ }^{\circ} \mathrm{C}$. A quantity of $500 \mu \mathrm{l}$ of the solubilizing solution (dimethyl sulfoxide/ethanol at $1: 1 \mathrm{vol} / \mathrm{vol}$ ) was added to each well and shaken to dissolve the crystals. The absorbance was read with a VMax microplate reader (Molecular Devices, Sunnyvale, CA, USA) at $570 \mathrm{nM}$, and the relative cell proliferation was expressed as a percentage of the control.

\section{Western blotting}

The cells were detached using a cell scraper and pelleted in 1.5-ml microcentrifuge tubes, then lysed with cell lysis buffer $\left[150 \mathrm{mM} \mathrm{NaCl}, 1.0 \%\right.$ IGEPAL $^{\circ}$ CA-630 (SigmaAldrich), $0.5 \%$ sodium deoxycholate, $0.1 \%$ sodium dodecyl sulfate (SDS), $50 \mathrm{mM}$ Tris, $\mathrm{pH}$ 8.0; Thermo Fisher Radioimmunoprecipitation Assay (RIPA) Lysis and Extraction Buffer, catalogue number 89901, Pierce Biotechnology/Thermo Fisher Scientific, Rockford, IL, USA] containing $1 \%$ protease inhibitor and phosphatase inhibitor cocktail. The protein concentration was determined using a Bio-Rad protein assay (Bio-Rad Laboratories). Proteins $(30 \mu \mathrm{g})$ from each sample were separated by $4-12 \%$ SDS-polyacrylamide gel electrophoresis and electrically transferred to a polyvinylidene difluoride membrane (BioRad Laboratories). The membranes were blocked in $5 \%$ nonfat milk in Tris-buffered saline and Tween 20 (TBS-T) for $1 \mathrm{~h}$ and then incubated with primary antibodies (Santa Cruz Biotechnology) at $4{ }^{\circ} \mathrm{C}$ overnight. The membranes were washed three times for 10 minutes in TBS-T and incubated with corresponding secondary antibodies (Cell Signaling Technology) conjugated to horseradish peroxidase anti-rabbit (or anti-mouse) immunoglobulin G (IgG) in $5 \%$ nonfat milk in TBS-T for $1 \mathrm{~h}$ at room temperature, followed by three washes for 10 minutes. Immunoreactivity was detected by enhanced chemiluminescence Western blotting detection reagents (Amersham ECL Plus; GE Healthcare Life Sciences, Piscataway, NJ, USA). The Western blot quantitation was performed using ImageJ software (http://rsb.info.nih.gov/ij/download.html; National Institutes of Health, Bethesda, MD, USA).

\section{Small interfering RNA transfection}

SUM149 cells were transfected with pooled small interfering RNAs (siRNAs) targeting IFITM1, STAT1, STAT2, BRG1, IFN 2 2, and IRF7. All of the pooled siRNAs contained a mixture of three target-specific 20- to 25-nt siRNAs. For IFITM1 knockdown, the individual siRNAs used were siRNA 1 (sc-44549A), siRNA 2 (sc-44549B), and siRNA 3 (sc-44549). For STAT1 and STAT2 knockdown, both individual and pooled siRNAs were used. The individual siRNAs for STAT1 were siRNA 1 (sc-44123A), siRNA 2 (sc-44123B), and siRNA 3 (sc44123), and the individual siRNAs for STAT2 were siRNA 1 (sc-29492A), siRNA 2 (sc-29492B), and siRNA 3 (sc29492). siBRG1 (sc-29827), siIRF7 (sc-38011), small interfering interferon $\alpha 2$ (siIFN 2 ; sc-63324), and scrambled RNA (siCon; sc-37007) were purchased from Santa Cruz Biotechnology. The transfection reagent used was Lipofectamine $2000^{\text {mix }}$ from Life Technologies (Carlsbad, CA, USA). IBC cells were seeded overnight and then transfected at a density of 50-60\% confluence with $60-100$ $\mathrm{nM}$ of targeted siRNAs or siCon. Transfected cells were maintained in culture for 24-72 $\mathrm{h}$ before being harvested and further analyzed. We should note that the knockdown efficiency of individual siRNAs targeting IFITM1, STAT1, and STAT2 was not statistically significantly different from that of the pooled siRNAs; hence, the pooled siRNAs were used for the functional studies.

\section{Short hairpin RNA transfection}

SUM149 cells were transfected with IFITM1 short hairpin RNA (shRNA) plasmid (h) (shIFITM1; sc-44549-SH) or control shRNA (shControl; sc-108060) plasmid, both of which were purchased from Santa Cruz Biotechnology. The IFITM1 shRNA plasmid was a pool of three different shRNA plasmids: SHA, SHB, and SHC. sc44549-SHA: hairpin sequence: GATCCCACACTTCTC AAACCTTCATTCAAG AGATGAAGGTTTGAGAAG TGTGTTTTT; corresponding siRNA sequences (sc44549A): sense: CACACUUCUCAAACCUUCAtt; antisense: UGAAGGUUUGAGAAGUGUGtt; sc-44549SHB: hairpin sequence: GATCCCTGTGACAGTCTAC CATATTTCAAGAGAATA TGGTAGACTGTCACAGTT TTT; corresponding siRNA sequences (sc-44549B): sense: CUGUGACAGUCUACCAUAUtt; antisense: AUAUGGU AGACUGUCACAGtt; sc-44549-SHC: hairpin sequence: GATCCCTGTCTACAGTGTCATTCATTCAAGAGATGA ATGACA CTGTAGACAGTTTTT; corresponding siRNA sequences (sc-44549C): sense: CUGUCUACAGUGUCA UUCAtt; antisense: UGAAUGACACUGUAGACAGtt. SUM149 cells were seeded into 6-well plates, and at 60$70 \%$ confluence they were transfected with $6-10 \mu \mathrm{g}$ of shIFITM1 or shControl plasmid using Lipofectamine $2000^{\text {max }}$ reagent according to the manufacturer's instructions. The transfected cells were incubated for $24-72 \mathrm{~h}$, 
and the knockdown was confirmed by Western blot analysis and real-time polymerase chain reaction (RT-PCR).

\section{RNA isolation and RT-PCR analysis}

Total RNA was isolated from cultured cells using a QIAGEN RNeasy Mini Kit Qiagen (catalogue number 74104; QIAGEN, Valencia, CA, USA) according to the manufacturer's protocol. First-strand complementary DNA (cDNA) synthesis was performed using $2.5 \mu \mathrm{g}$ of total RNA using Invitrogen SuperScript Reverse Transcriptase (Thermo Fisher Scientific, Carlsbad, CA, USA). cDNA was amplified in a $25-\mu \mathrm{l}$ PCR mixture containing $1 \mu \mathrm{l}$ of deoxynucleotide triphosphates, $1 \times \mathrm{PCR}$ buffer, $2.5 \mathrm{mM} \mathrm{MgCl}_{2}$, and $1 \mathrm{U}$ of DNA Taq polymerase (Promega, Madison, WI, USA) with 25 pmol of primers specific for human IFITM1, which were obtained from Integrated DNA Technologies (Coralville, IA, USA) (sense: 5'-GGATTTCGGCTTG TCCCGAG-3', antisense: 5'-CCATGTGGAAGGGAGG GCTC-3'), STAT1 (sense: 5'-GGCACCAGAACGAAT GAGGG-3', antisense: 5' - CCATCGTGCACATGGTGG AG-3'), PLSCR1 (sense: 5'-CATTCACCGGGCTCTCT AC-3', antisense: 5'-GGCAGCTGGGCAATCTTGCA-3'), STAT2 (sense: 5'-GCAGCACAAT TTG GGAA-3', antisense: 5' -ACAGGTGTTTCGAGAACTGGC-3'), IRF9 (sense: 5' -TTCTGTCC CTGGTGTAGAGCCT-3', antisense: 5' - TTTCAGGACACGATTATCACGG-3'), IRF7 sense: 5' -GAGCCCTTACCTCCCCTGTTAT-3', antisense: 5' -CCACTGCAGCCCCTCATAG-3', IFI27 (sense: 5' GCCTCTGGCTCTGCCGTAGTT-3', antisense: $5^{\prime}$-AT GGAGGACGAGGCGATTCC-3'), IFIT1 (sense: 5'-TCT CAGAGGAGCCTGGCTAA-3', antisense: 5' -CCAGAC TATCCTT GACCTGATGA-3'), OAS1 (sense: 5'-TGA GGTCCAGGCTCCACGCT-3', antisense: 5'-GCAGGT CGGTGCACTCCTCG-3'). The PCR experiment was performed according to the manufacturer's protocol for Applied Biosystems Power SYBR ${ }^{\circ}$ Green PCR Master Mix and RT-PCR (PN 4367218; Life Technologies, Carlsbad, CA, USA) as follows: enzyme activation step: 10-minute hold at $95{ }^{\circ} \mathrm{C}$ for AmpliTaq Gold ${ }^{\circ}$ enzyme activation, followed by PCR amplification steps (40 cycles); and denaturation step: 15 seconds at $95^{\circ} \mathrm{C}$, annealing/extension step: 60 seconds at $60{ }^{\circ} \mathrm{C}$. Pumilio RNA-binding family member 1 (PUM1) was used as the internal control (sense: 5'-TCACCGAGGCCCCTCTGAACCCTA-3'; antisense: 5 '-GGCAGTAATCTCCTTCTGCATCC T-3'). The reproducibility of the quantitative measurements was evaluated by three independent cDNA syntheses and PCR amplification from each preparation of messenger RNA (mRNA). The relative mRNA expression level was determined as a ratio of the signal intensity to that of PUM1.

\section{Cell-cycle analysis}

SUM149 cells were seeded at a density of $3.0 \times 10^{5}$ cells per well in 6-well culture plates overnight so that cells could attach. The cells were transfected with small interfering IFITM1 or control siRNA for $24 \mathrm{~h}$. At the end of the transfection period, the cells were harvested by trypsinization and washed once with phosphate-buffered saline (PBS), $\mathrm{pH}$ 7.4. The cells were fixed in $100 \%$ ice-cold ethanol for $24 \mathrm{~h}$ and stained with $50 \mu \mathrm{l} / \mathrm{ml}$ of $2 \mathrm{mg} / \mathrm{ml}$ propidium iodide stock with $10 \mu \mathrm{l} / \mathrm{ml}$ of RNase A and incubated for 30 minutes at room temperature. The DNA contents of $5 \times 10^{5}$ cells were determined using a BD LSR II flow cytometer (BD Biosciences, San Jose, CA, USA). The flow cytometry data were analyzed using FlowJo software (Tree Star, Ashland, OR, USA) to determine the percentages of the cells at each phase of the cell cycle. Three separate experiments were performed in triplicate, and IFITM1 knockdown was confirmed by Western blot analysis after each transfection.

\section{Immunofluorescence microscopy}

SUM149 and SUM190 IBC cells were plated onto chambered slides and, after overnight incubation for attachment, were treated with or without IFN for a further $24 \mathrm{~h}$. The cells were washed in PBS and fixed with $100 \%$ methanol for 10 minutes, and then washed three times for 10 minutes each before being permeabilized with $0.1 \%$ Triton X-100 in PBS for 10 minutes, followed by three washes for 5 minutes and then blocking with $5 \%$ normal horse serum for $1 \mathrm{~h}$. The cells were then incubated with anti-IFITM1 primary antibody overnight, after which they were washed three times in PBS for 10 minutes, followed by staining with fluorescein isothiocyanate-conjugated goat anti-mouse IgG secondary antibody $(4 \mu \mathrm{g} / \mathrm{ml})$ for $1 \mathrm{~h}$. The coverslips were mounted on glass slides with VECTASHIELD Mounting Medium (Vector Laboratories, Burlingame, CA, USA) containing 4',6-diamidino-2-phenylindole for nuclear counterstaining, and samples were incubated at room temperature for $24 \mathrm{~h}$ before being analyzed using a Leica confocal microscope equipped with Leica Application Suite Advanced Fluorescence Lite 2.6.0 Build 7266 software (Leica Biosystems, Buffalo Grove, IL, USA).

\section{Enzyme-linked immunosorbent assay}

Human IFN $\alpha$ levels were measured by enzyme-linked immunosorbent assay (ELISA; PBL Interferon Source; PBL Assay Science, Piscataway, NJ, USA). A quantity of $5 \times 10^{5}$ SUM149, SUM190, and MCF-7 cells were seeded into 6-well plates and incubated at $37{ }^{\circ} \mathrm{C}$ overnight so that the cells would attach. The cells were then treated with $100 \mathrm{U} / \mathrm{ml}$ human recombinant IFNa or transfected with siIRF7 and siIFN $\alpha$ for $48 \mathrm{~h}$. Cells and supernatants were harvested and kept at $-80{ }^{\circ} \mathrm{C}$ until analysis. Protein was extracted by sonication in RIPA buffer supplemented with protease and phosphatase inhibitors. Supernatants and lysates were purified by centrifugation and 
analyzed for the presence of IFN $\alpha$ according to the manufacturer's instructions.

\section{Interferon a receptor neutralization}

SUM149 cells were treated with $5 \mu \mathrm{g} / \mathrm{ml}$ anti-IFNAR1/2 mouse anti-human IFN $\alpha / \beta$ receptor monoclonal antibody (catalogue number MAB1155; EMD Millipore) for $24 \mathrm{~h}$. The cells were harvested using a cell scraper and then processed for Western blot analysis.

\section{IFITM1 luciferase promoter assay}

SUM149 and SUM190 cells were seeded in 24-well tissue culture plates overnight for attachment before transfection. The cells were transfected using Lipofectamine $2000^{\mathrm{m}}$ transfection reagent according to the manufacturer's recommendations. Four microliters of Lipofectamine $2000^{\mathrm{mm}}, \quad 0.8 \mu \mathrm{g}$ of plasmid DNA (pGL3-Basic [Promega, Madison, WI, USA], pGL3-IFITM1 [-750/ $-1]$, pGL3-IFITM1 [-200/-1]), and $0.01 \mu \mathrm{g}$ of the pRLCMV Renilla (Promega) were diluted individually in $125-\mu \mathrm{l}$ aliquots of Gibco Opti-MEM Reduced Serum Medium (Life Technologies). Cells were incubated for $24 \mathrm{~h}$ after transfection and treated with IFN $\alpha(200 \mathrm{U})$, and then the luciferase and Renilla activities were measured 24 h later using the Promega Dual-Luciferase Reporter Assay System according to the manufacturer's instructions. To confirm that the luciferase activity of each construct was caused by IFN $\alpha$, the activity of each construct was assayed in the presence and absence of IFN $\alpha$. In a separate set of samples, cells were transfected with the $-750 /-1$ IFITM1 promoter construct for $24 \mathrm{~h}$, followed by transfection with siSTAT1 and siSTAT2 for a further $24 \mathrm{~h}$ and subsequent determination of promoter activity. Renilla activity was also assayed to standardize sample transfection efficiencies.

\section{Statistical analysis}

At least three separate experiments were performed for each measurement. All quantitative data were expressed as mean \pm standard deviation. Comparisons between two groups were analyzed using $t$ tests in Excel 2010 (version 14.0; Microsoft, Redmond, WA, USA), with $P$ values less than 0.05 considered statistically significant.

\section{Results}

IFITM1 is overexpressed in triple-negative SUM149 inflammatory breast cancer cells

To identify the factors contributing to the aggressive phenotype of IBC cells, we measured the expression of IFITM1, an ISG linked to tumor progression, in three IBC cell lines: triple-negative SUM149, HER2-amplified SUM190 and MDA-IBC-3, and the non-IBC cell line MCF-7 (ER+). We found that IFITM1 was highly expressed in SUM149 cells at the protein (Fig. 1a) and
mRNA (Fig. 1b) levels, but that it was not expressed in SUM190, MDA-IBC-3, and MCF-7 cells (Fig. 1a). Immunofluorescence confirmed that IFITM1 was overexpressed in SUM149 cells and that it was localized primarily in the cytoplasmic and plasma membrane regions of the cells (Fig. 1c). We should note that there are only a few human IBC cell lines (i.e., SUM149, SUM190, MDA-IBC-3, MARY-X, and FC-IBC-02) available for studying this complex disease and that these cell lines have molecular signatures that are distinct from each other. Overexpression of IFITM1 in the SUM149 cell line alone suggests that it might be an important marker in these cells.

\section{IFITM1 knockdown inhibits proliferation, colony formation, and invasion in SUM149 cells}

To assess the functional significance of IFITM1 expression in SUM149 cells, siRNAs and shRNAs were used to knock down IFITM1. Three different siRNAs (IFITM1siRNA1, IFITM1-siRNA2, and IFITM1-siRNA3) and IFITM1-shRNA were used. Cells were transfected with the individual siRNAs (siRNA-1 and siRNA-2), the pooled siRNA (siRNA-3), shRNA (shIFITM1), scrambled control (siCon), or shRNA control (shCon) for $72 \mathrm{~h}$. We found that the individual siRNAs and the pooled siRNA completely reduced IFITM1 expression in SUM149 cells (Fig. 2a) and that loss of IFITM1 reduced the proliferation of SUM149 cells by approximately 52-63 \% (Fig. 2b). Cell-cycle analysis revealed that the inhibitory effect of IFITM1 knockdown in SUM149 cells was due in part to $\mathrm{G}_{1}$ arrest (Additional file 1: Figure S1A), which was associated with downregulation of cyclin D1 and cyclin E (Additional file 1: Figure S1B). Additionally, IFITM1 knockdown dramatically reduced the ability of SUM149 cells to form 2-D colonies (Fig. 2c, left and right panels), to grow in an anchorage-independent manner (Fig. 2d, left and right panels), and to migrate and invade (Fig. 2e, left and right panels). We also determined that IFITM1 shRNA completely suppressed IFITM1 expression in SUM149 cells (shown in Fig. 3a), which resulted in inhibition of cell proliferation by up to $54 \%$ (Fig. 3b), migration (Fig. 3c), and 2-D colony formation (Fig. 3d, left and right panels).

\section{Enhanced IFNa signaling drives IFITM1 overexpression in SUM149 cells}

Type I IFN $\alpha / \beta$ induce ISGs by binding to their receptors IFNAR1/2 and activating the canonical JAK-STAT signaling pathway. To determine whether elevated IFNa signaling is responsible for driving constitutive IFITM1 overexpression in IBC cells, we first measured IFNa levels in SUM149, SUM190, and non-IBC MCF-7 cells using ELISA, and we found that IFN $\alpha$ protein level was significantly higher in the lysates of SUM149 and 
A

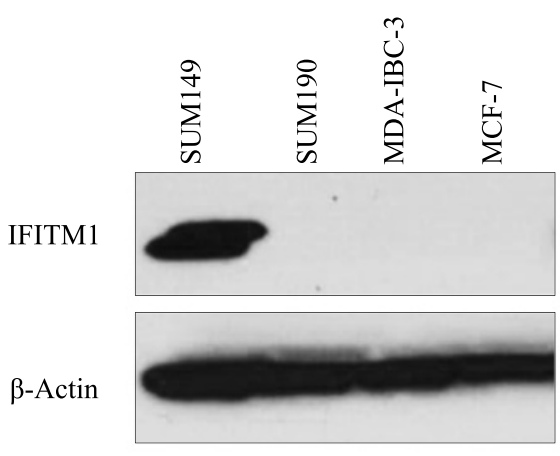

B

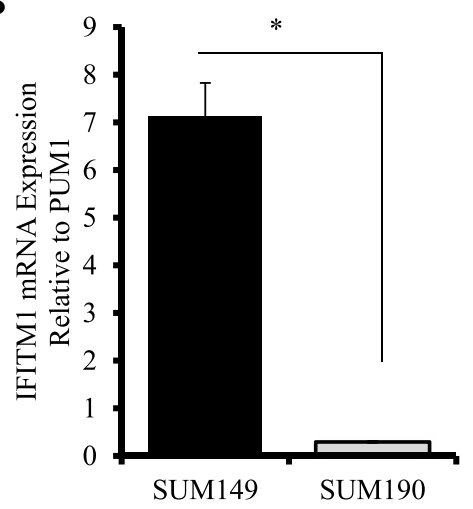

C
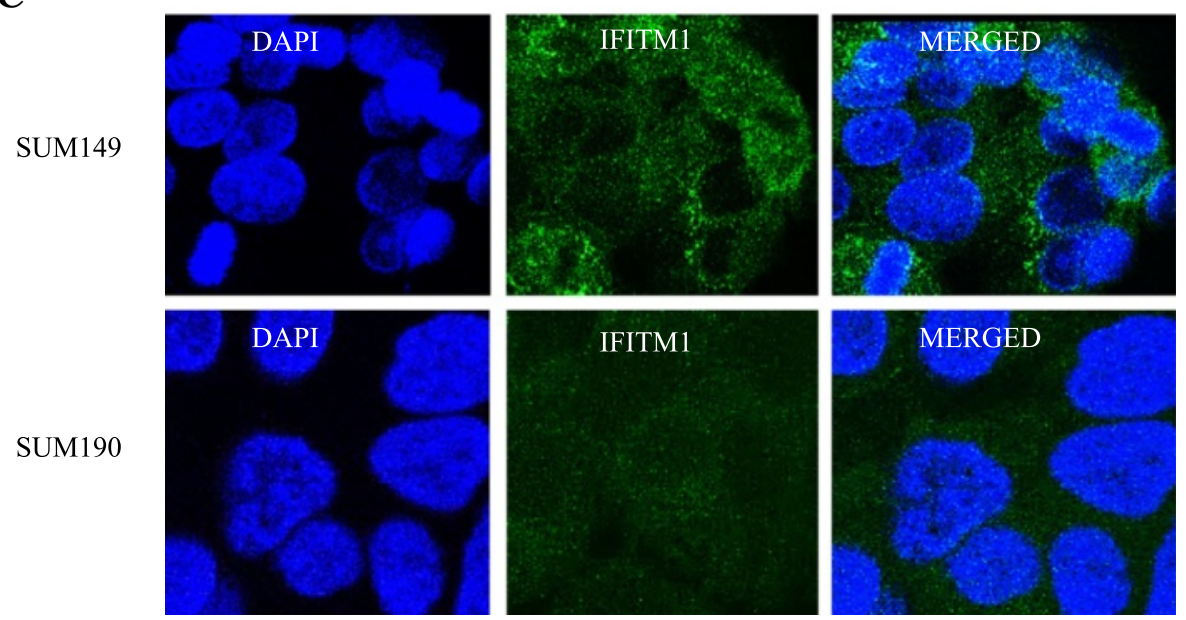

Fig. 1 Interferon-induced transmembrane protein 1 (IFITM1) protein and messenger RNA (mRNA) expression in breast cancer cells. a IFITM1 protein expression in the triple-negative SUM149 cells, human epidermal growth factor receptor 2-overexpressing SUM190 and MDA-IBC-3 cells, and non-inflammatory breast cancer (non-IBC) MCF-7 cells. The protein expression was assessed by Western blot analysis, with -actin used as a loading control. b IFITM1 mRNA expression in SUM149 and SUM190 cells. The mRNA levels were determined by real-time polymerase chain reaction, and the fold change for each cell line was calculated against the Pumilio RNA-binding family member 1 (PUM1) internal control gene. Each value shown is the mean \pm standard deviation from three independent experiments. ${ }^{*} P<0.05$. c IFITM1 protein expression and localization profiles of SUM149 and SUM190 IBC cells determined by immunofluorescence. The images of the cells were captured using a Leica confocal microscope equipped with Leica Application Suite Advanced Fluorescence Lite 2.6.0 Build 7266 software. DAPI 4',6-diamidino-2-phenylindole

SUM190 IBC cells compared with non-IBC MCF-7 cells (data not shown). Notably, RT-PCR analysis revealed that IFN $\alpha$ mRNA level was approximately $53 \%$ higher in SUM149 cells compared with SUM190 cells (Fig. 4b). Next, we determined the effect of IFN $\alpha$ suppression in SUM149 and SUM190 cells by transfecting these cells with siRNAs targeting either IFN $\alpha$ and/or its transcriptional regulator IRF7. As shown in Fig. 4a (left panel), siRNA knockdown of IFN $\alpha$ significantly reduced IFN $\alpha$ level in the supernatant and lysate of SUM149 cells, whereas knockdown of IRF7, either alone or combined with siIFN $\alpha$, significantly reduced IFN $\alpha$ level in the lysate and supernatant of SUM149 cells, but the differences were not significant in SUM190 cells (Fig. 4a, right panel). Western blot analysis also confirmed that knockdown of IFN $\alpha$ and IRF7, either individually or combined, markedly reduced IFITM1 protein expression in SUM149 cells (Fig. 4c). STAT1 and STAT2 proteins were also reduced following IFN $\alpha$ and IRF7 knockdown (Fig. 4c). Additionally, we found that blockade of the IFN $\alpha$ receptors IFNAR $1 / 2$ with a neutralizing monoclonal antibody (IFNAR-Ab) completely inhibited IFITM1 protein expression in SUM149 cells (Fig. 4d, left and right panels), and it markedly reduced STAT1 and STAT2 protein levels in these cells. Together, these findings confirm that constitutive overexpression of IFITM1 in SUM149 cells is driven in part by activation of the IFN $\alpha$ signaling pathway. Notably, we also performed comparative genomic hybridization $(\mathrm{CGH})$ analysis to assess DNA copy number changes for IFITM1 and other 


\section{A}

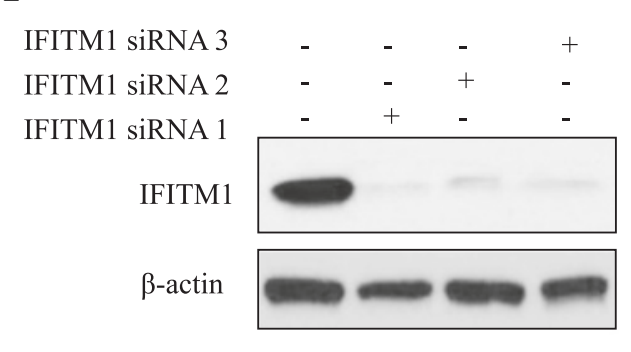

$\mathbf{C}$

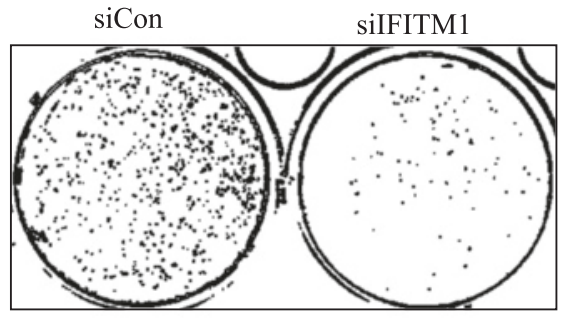

D
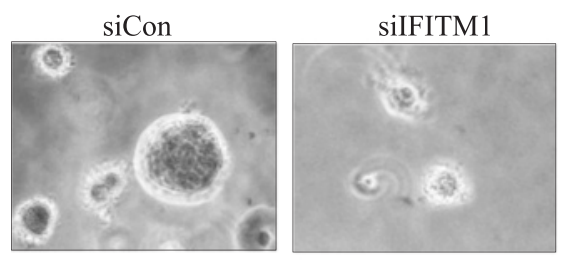

$\mathbf{E}$
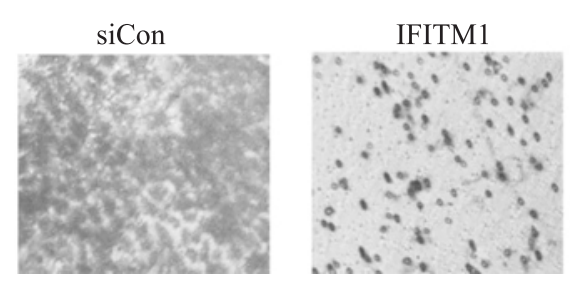
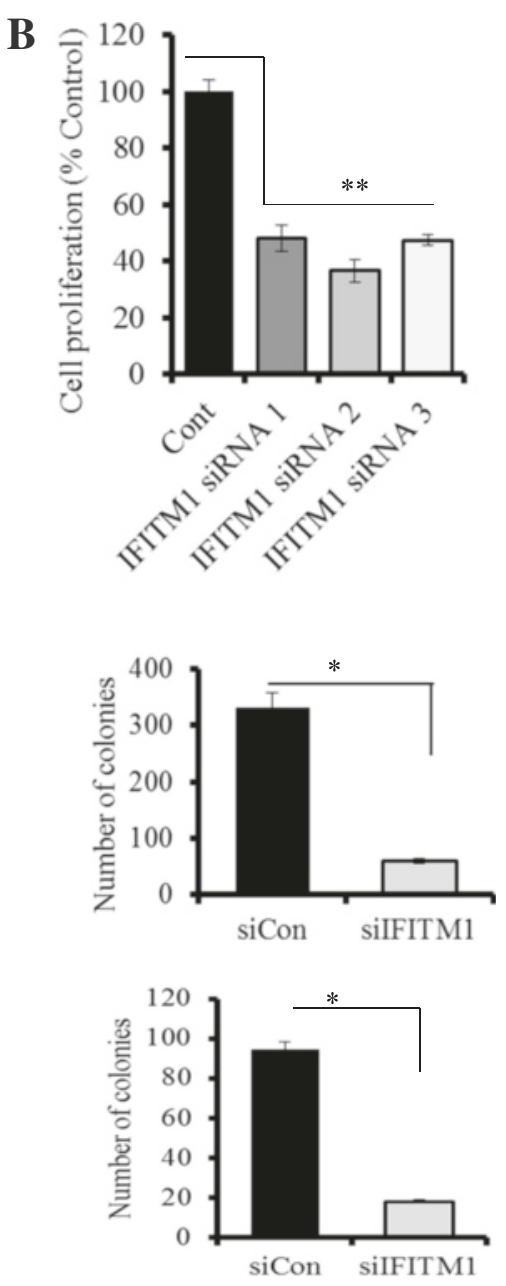

F

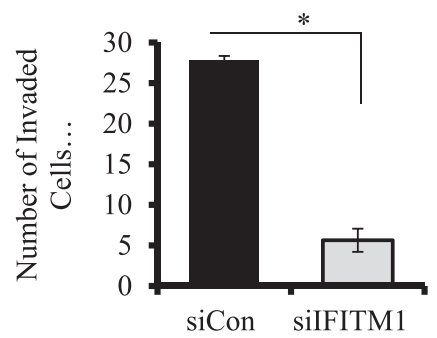

Fig. 2 Effects of small interfering RNA (siRNA) knockdown of interferon-induced transmembrane protein 1 (IFITM1) on proliferation and tumorigenic potential of SUM149 cells. a Western blot analysis of SUM149 cells showing the protein levels of IFITM1. The IFITM1 gene was knocked down using three separate siRNAs (siRNA 1, siRNA2, and siRNA 3), and the control samples were transfected with a negative control siRNA (siCon) for 72 h. b Cell proliferation after $72 \mathrm{~h}$ of IFITM1 knockdown with three separate siRNAs. A 3-(4,5-dimethylthiazol-2-yl)-2,5-diphenyltetrazolium bromide assay was performed to assess cell proliferation. Bars represent mean \pm standard deviation (SD). ${ }^{*} P<0.005$ for siRNA knockdown compared with siCon. c 2-D colony formation showing the effects of silencing of IFITM1 in SUM149 cells on the formation of colonies in a 2-D surface. The images of the plates were captured using the ChemiDoc ${ }^{\mathrm{TM}}$ XRS System equipped with Image Lab $\mathrm{b}^{\mathrm{TM}}$ software, then transformed and quantified by using ImageJ software. $\mathbf{d}$ Left panel: Anchorage-independent growth in soft agar showing the effect of IFITM1 knockdown on colony formation in SUM149 cells. The representative images were captured using a phase-contrast microscope equipped with an Olympus camera (original magnification, $\times 200)$. Right panel: The colonies were imaged using the ChemiDoc ${ }^{\mathrm{TM}}$ XRS System and quantified using ImageJ software. e Effect of IFITM1 knockdown on cell invasion and migration in SUM149 cells as assessed by Transwell Matrigel assay (Corning, Corning, NY, USA). The invaded cells were stained with crystal violet and imaged. $\mathbf{f}$ Quantitation of the number of invaded cells in SUM149 cells. The data presented are mean \pm SD of three replicates. ${ }^{*} P<0.05$ 
A

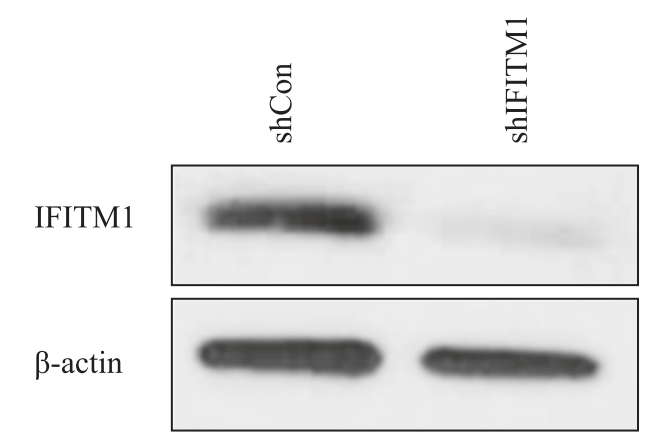

C

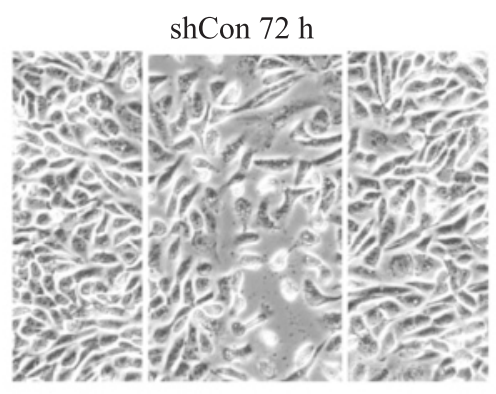

B

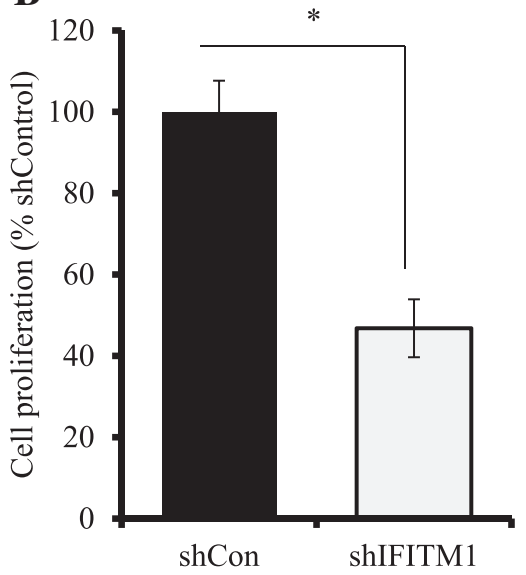

shIFITM1 $72 \mathrm{~h}$

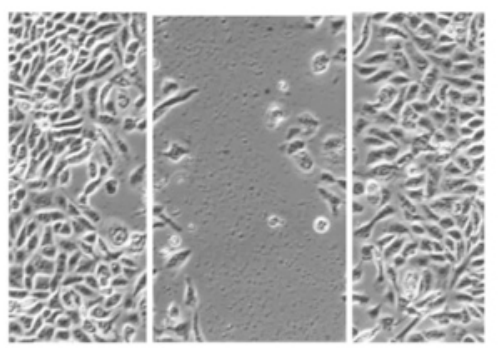

D
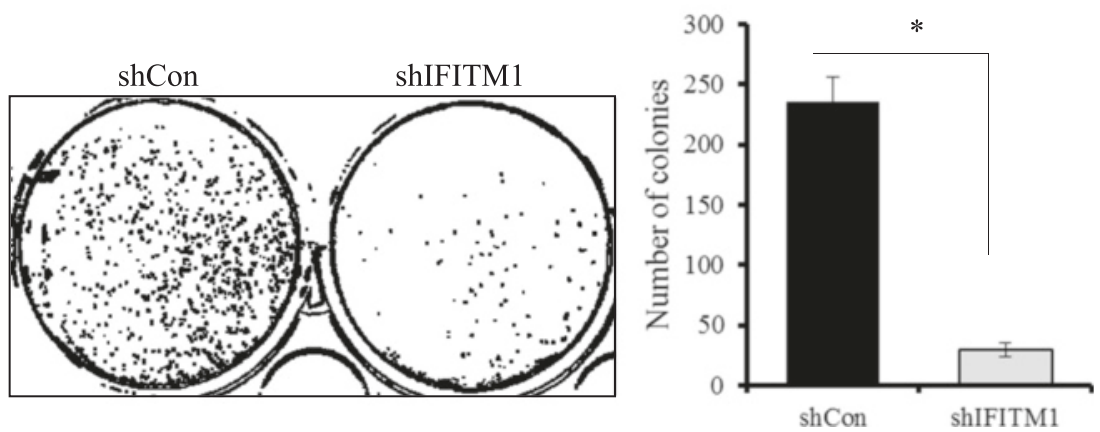

Fig. 3 Effects of short hairpin RNA (shRNA) knockdown of interferon-induced transmembrane protein 1 (shIFITM1) on cell proliferation, migration, and colony formation in SUM149 cells. a Western blot analysis was used to confirm the shRNA knockdown of IFITM1 in SUM149 cells. b Cell proliferation was assessed by 3-(4,5-dimethylthiazol-2-yl)-2,5-diphenyltetrazolium bromide assay in SUM149 cells that were transfected with shRNA for $24 \mathrm{~h}$ and maintained in culture for a further $48 \mathrm{~h}$. The assay results showed that the knockdown of IFITM1 reduced cell proliferation by up to $52 \%$ in SUM149 cells compared with the short hairpin control cells (shCon). c Cell migration was assessed by wound-healing assay. $\mathbf{d}$ Left panel: 2-D colonies formed by SUM149 cells with and without shRNA knockdown. Right panel: Quantification of the number of colonies. ${ }^{*} P<0.05$

components of the IFN signaling pathway in SUM149 cells. CGH data revealed that there was no significant change in the DNA copy number for IFITM1 in SUM149 cells; however, there was a $27.5 \%$ gain in copy number for IFN $\alpha$ and IFN $\beta$ (data not shown), which are the ligands that activate the JAK-STAT signaling pathway. These findings suggest that overexpression of IFITM1 in SUM149 cells may be due in part to increased expression of IFNa (observed at the DNA, mRNA, and protein levels), which activates the JAKSTAT signaling pathway.
STAT2 is a critical regulator of IFITM1 expression in SUM149 cells

STAT1 and STAT2 are transcription factors that play a critical role in regulating type I IFN $\alpha / \beta$ signaling. To evaluate the role of STAT1 and STAT2 in the regulation of IFITM1 in SUM149 cells, siRNAs were used to knock down their expression. As shown in Fig. 5a (left and right panels), knockdown of STAT2 completely suppressed IFITM1 expression in SUM149 cells, whereas knockdown of STAT1 did not significantly reduce IFITM1 protein expression in these cells. Similar results 

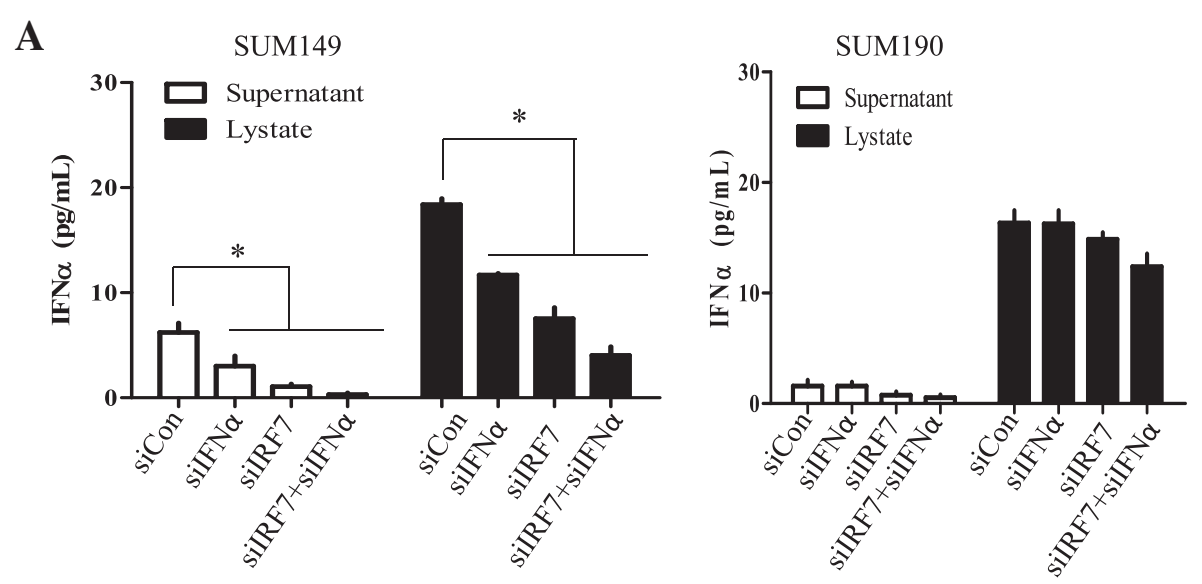

B

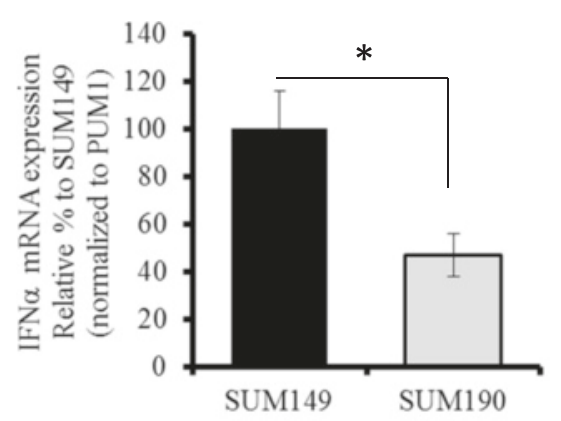

C

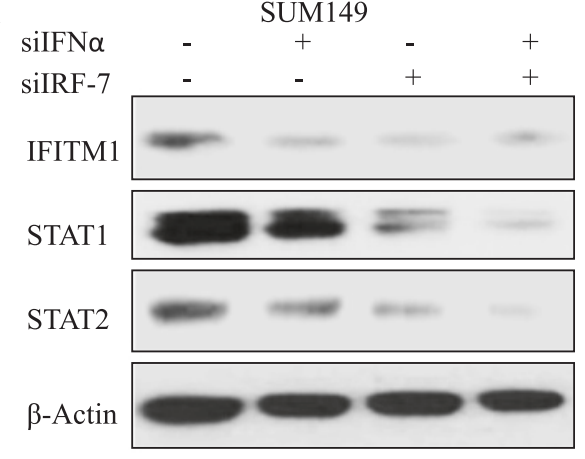

D
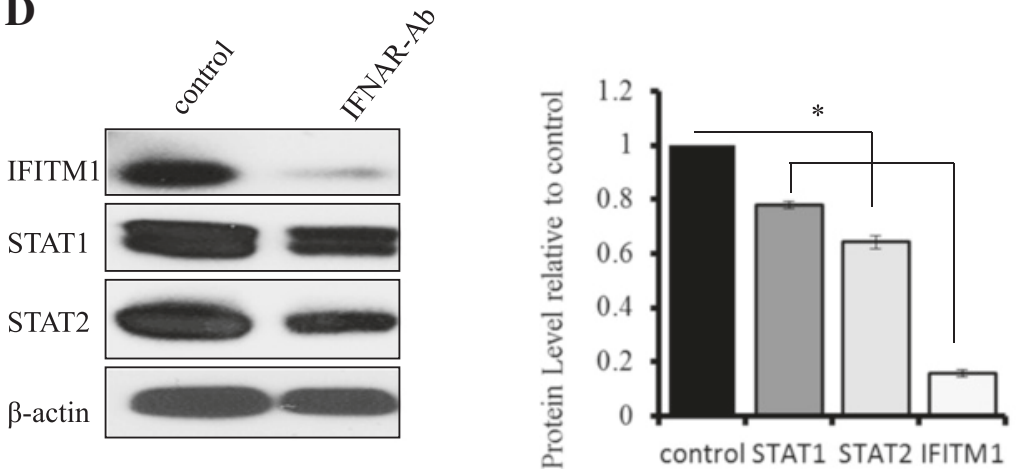

Fig. 4 Regulation of interferon-induced transmembrane protein 1 (IFITM1) by the interferon signaling pathway in SUM149 cells. a Human interferon a (IFNa) levels were measured in the supernatant and lysates of SUM149 and SUM190 cells after the knockdown of IFNa and interferon regulatory factor 7 (IRF7) using small interfering RNA (siRNA). Measurements of IFNa were done with an enzyme-linked immunosorbent assay (PBL Interferon Source; PBL Assay Science, Piscataway, NJ, USA) according to the manufacturer's instructions. The data presented are mean \pm standard deviation. ${ }^{*} P<0.05$ compared with siControl. b IFNa messenger RNA (mRNA) levels in SUM149 and SUM190 IBC cells measured by real-time polymerase chain reaction. ${ }^{*} P<0.05$. $\mathbf{c}$ Western blot analysis of IFITM1, signal transducer and activator of transcription 1 (STAT1), and STAT2 protein expression following the suppression of IRF7 and IFNa in SUM149 cells. d Left panel: Western blot showing the protein levels of IFITM1, STAT1, and STAT2 after interferon receptor (IFNR)-a/ was neutralized using mouse anti-human IFNR-a/ chain 2 monoclonal antibody (Ab) in SUM149 cells. Right panel: Quantification of IFITM1 protein expression from the Western blots using ImageJ software. ${ }^{*} P<0.05$. PUM1 Pumilio RNA-binding family member 1

were observed using two additional siRNAs targeting STAT1 (siRNA1 and siRNA2) (Additional file 2: Figure S2A) and STAT2 (siRNA1 and siRNA2) (Additional file 2: Figure S2B). Additionally, knockdown of STAT2 reduced cell proliferation (Fig. 5b, upper left and right panels), colony formation (Fig. 5c, upper left and right panels), and migration (Fig. 5d, right panel) in SUM149 cells, whereas knockdown of STAT1 did not significantly alter the aggressive phenotype of these cells (Fig. 5b and c, lower left and right panels; Fig. 5d, middle panel). 
A siSTAT1 1 - $\quad+\quad+\quad+$

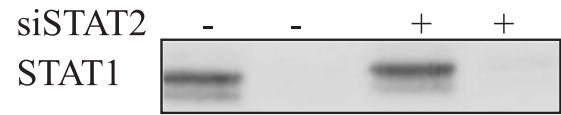

STAT2

IFITM1

$\beta$-actin

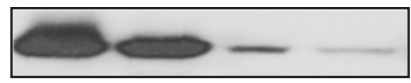

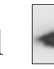

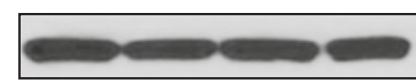

B

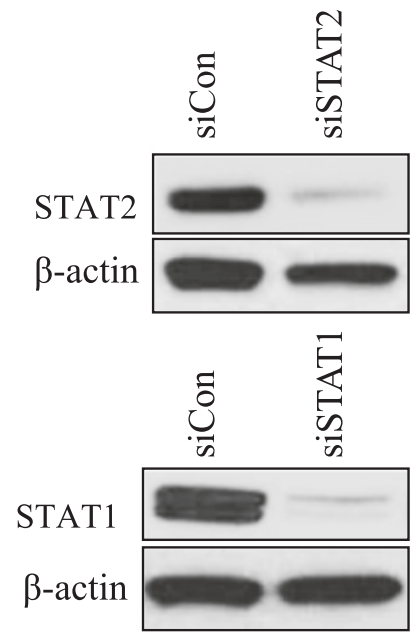

$\mathrm{C}$

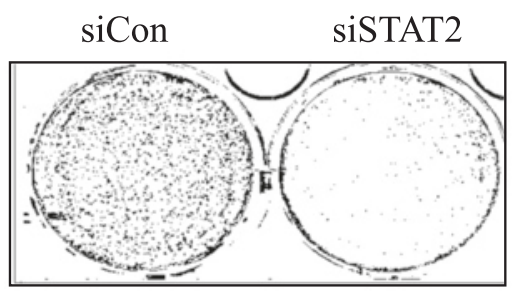

siCon

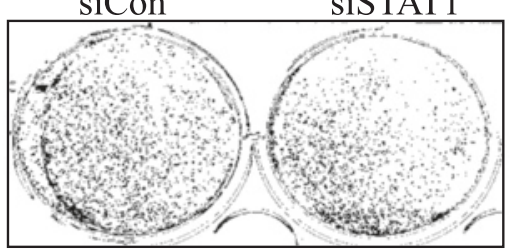

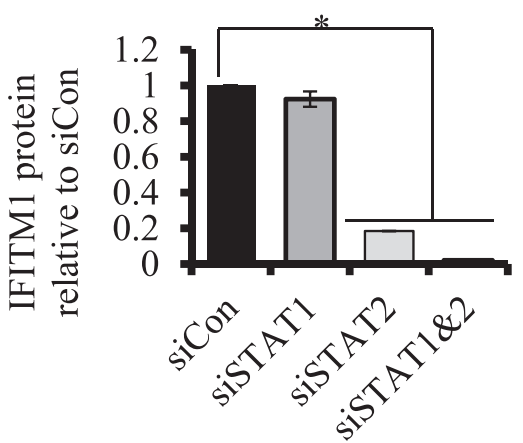
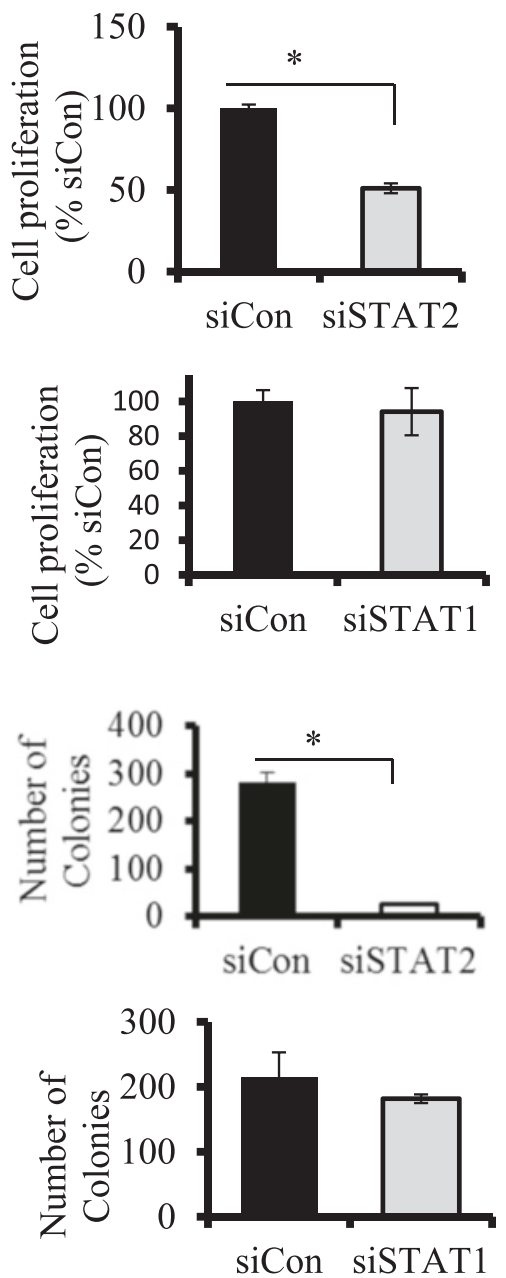

D

siCon $72 \mathrm{~h}$

siSTAT1 $72 \mathrm{~h}$

siSTAT2 $72 \mathrm{~h}$
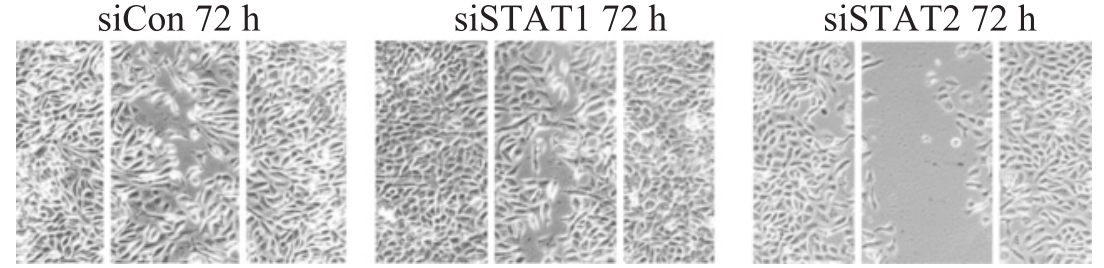

Fig. 5 (See legend on next page.) 
(See figure on previous page.)

Fig. 5 Effects of signal transducer and activator of transcription 1 (STAT1) andSTAT2 knockdown on interferon-induced transmembrane protein 1 (IFITM1) expression and tumorigenic potential of SUM149 cells. a Left panel: Western blots showing the protein levels of STAT1, STAT2, and IFITM1 after STAT1 and STAT2 genes were knocked down in SUM149 cells using siSTAT1 and siSTAT2. -Actin was used as a loading control. Left panel: Quantification of the protein levels of IFITM1 in the siSTAT1, siSTAT2, and siSTAT1/2 samples. IFITM1 levels were quantified using ImageJ software, were normalized to -actin, and were expressed relative to siControl. b Upper panel: Western blot of STAT2 knockdown in SUM149 cells and the effects of the knockdown on cell proliferation. Lower panel: Western blot of STAT1 knockdown in SUM149 cells and the effects of the knockdown on cell proliferation. c Left panel: Effects of STAT1 and STAT2 knockdown on 2-D colony formation in SUM149 cells. Right panel: Quantification of the colonies. $\mathbf{d}$ Wound-healing assay showing the effects of STAT1 and STAT2 knockdowns on the ability of SUM149 cells to migrate. ${ }^{*} P<0.05$

\section{BRG1 is a critical regulator of IFITM1 expression in SUM149 cells}

The IFITM1 promoter region has a nucleosome that requires remodeling to expose the interferon-stimulated response element (ISRE), IFN $\gamma$-activated site (GAS), and IRF sequences and to enable transcription factor binding. BRG1, the ATP subunit of the BAF chromatin remodeling complex, has been shown to be recruited by STAT2 to the promoter region of ISGs in the process of transcription. To assess the role of BRG1 in regulating IFITM1 expression, siRNA knockdown studies were performed in SUM149 cells, and BRG1 and IFITM1 protein was measured by Western blot analysis. As shown in Fig. 6, siRNA knockdown of BRG1 protein in SUM149 cells completely suppressed IFITM1 expression in these cells. These data suggest that STAT2 and BRG1 are critical regulators of IFITM1 expression in SUM149 cells with less significant involvement of STAT1 in the process.

STAT2 regulates IFITM1 promoter activity in SUM149 cells The promoter region of the IFITM1 gene contains ISRE, GAS, and IRF DNA sequences (Additional file 3: Figure S3) that provide binding sites for transcription factors such as STAT1, STAT2, and IRF9. Figure 7a shows schematic diagrams for the full-length IFITM1 promoter $(-1000 /+400)$, the two IFITM1 deletion constructs (IFITM1 - 750/-1 and IFITM1 - 200/-1), and the empty vector ( $\mathrm{pGL3)}$. A luciferase assay was used to measure
IFITM1 promoter activity in SUM149 and SUM190 cells following transfection of these cells with either pGL3b $-750 /-1$ or pGL3b $-200 /-1$. As shown in Fig. $7 b$, we found that IFITM1 promoter activity was higher in the cells transfected with the $-750 /-1$ construct as compared with $-200 /-1$, and in SUM149 cells as compared with SUM190 cells (data not shown). IFN treatment increased the promoter activity for both constructs significantly in SUM149 cells (Fig. 7b). To determine the functional significance of STAT1 and STAT2 on promoter activity, we knocked down STAT1 and STAT2 in the cells that were transfected with the $-750 /-1$ construct and measured the luciferase activity in the cells. We found that IFITM1 promoter activity was significantly lower in the STAT2 knockdown cells in SUM149 as compared with STAT1 (Fig. 7c), suggesting that STAT2 played a critical role in IFITM1 induction in these cells. STAT2 has been shown to form non-ISG factor 3 (non-ISGF3) complexes in which its homodimers bind to GAS consensus sequence on the promoters of a subset of ISGs and induce their transcription. Of the two constructs, the $-750 /-1$ construct has more TTA half-sites and TTC half-palindromes compared with the $-200 /-1$ construct, which may explain why it had higher luciferase activity. Taken together, these findings suggest that STAT2, not STAT1, plays a dominant role in regulating IFITM1 transcriptional activation in SUM149 cells through binding to multiple consensus sequences such as ISRE/IRF and GAS.

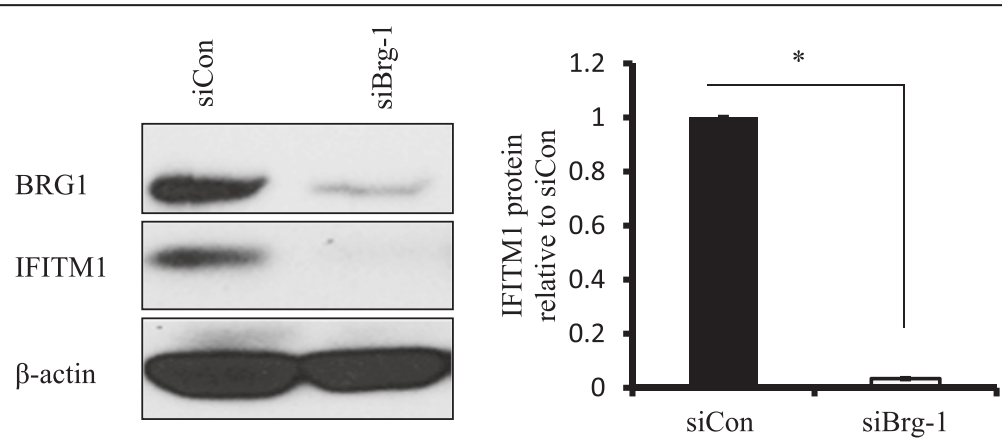

Fig. 6 Effects of brahma-related gene 1 (BRG1) knockdown on interferon-induced transmembrane protein 1 (IFITM1) expression in SUM149 cells. Left panel: Western blot showing the protein levels of BRG1 and IFITM1 after BRG1 gene was knocked down using siBRG1 for $48 \mathrm{~h}$ in SUM149 cells. -actin was used as a loading control. Right panel: Quantification of IFITM1 protein levels from the Western blots. ${ }^{*} P<0.05$ 
A
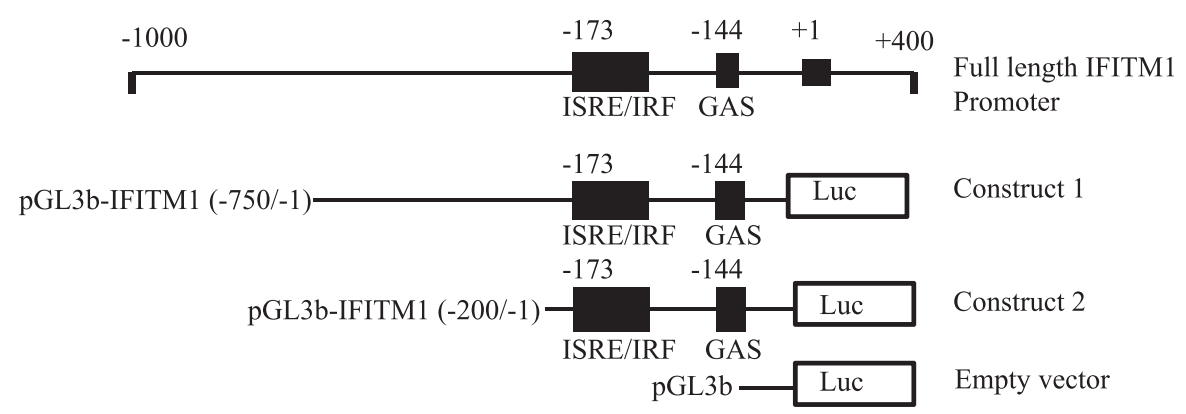

B

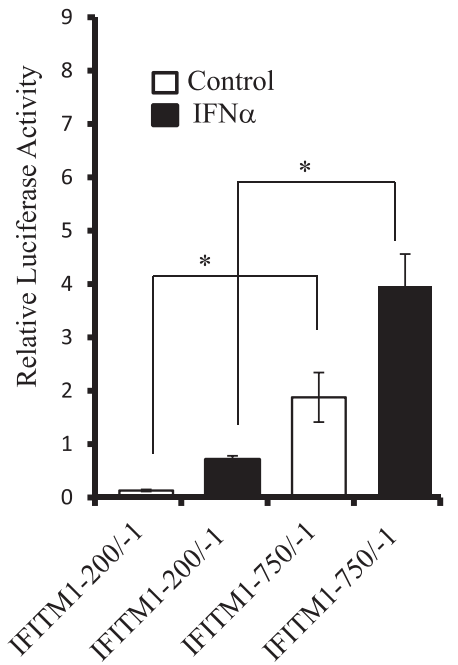

C

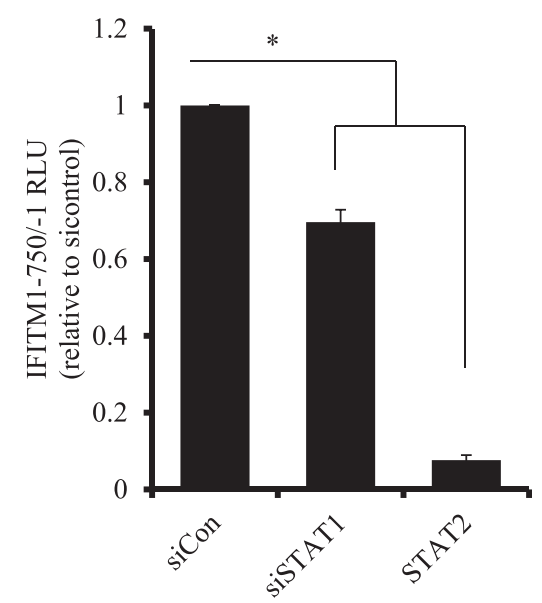

Fig. 7 Interferon-induced transmembrane protein 1 (IFITM1) promoter activity in SUM149 cells. a Schematic diagram of the IFITM1 promoter showing ATG transcription start site, interferon-stimulated response element (ISRE)/interferon regulatory factor (IRF), interferon gamma-activated site (GAS), TTA half-sites, and TTC half-palindromes; constructs; pGL3-IFITM1 - 750/-1, pGL3-IFITM1 - 200/-1, and the empty vector (pGL3). b Relative luciferase activity of the IFITM1 promoter region using the two deletion constructs (-750/-1 and $-200 /-1)$, along with interferon treatment in SUM149 cells. c Effects of signal transducer and activator of transcription 1 (STAT1) and STAT2 knockdown on the IFITM1 promoter activity using the $-750 /-1$ deletion construct. The luciferase activity was expressed relative to scrambled control RNA (siCon). The data presented are representative of triplicate experiments and are expressed as mean \pm standard deviation. ${ }^{*} P<0.05$. RLU stands for Relative Light Units (RLU). It is a unit that is based on light emitted by the luciferase-catalyzed chemiluminescent reaction

\section{Functional integrity of the IFNa signaling pathway in SUM149 cells}

Because IFITM1 was constitutively overexpressed in SUM149 cells, we next determined whether exogenous IFN $\alpha$ was capable of activating the IFN $\alpha$ signaling pathway in these cells. As shown in Fig. 8a, exogenous treatment with IFN $\alpha$ increased IFITM1 protein expression in both SUM149 and SUM190 cells within 6-8 h of treatment, with maximum induction at $24 \mathrm{~h}$; however, basal expression of IFITM1 was observed in SUM149 cells from time 0 but not in SUM190 cells until $6 \mathrm{~h}$ posttreatment with IFNo. Notably, exogenous IFN $\alpha$ also increased total STAT1 and STAT2 protein expression in both cell lines, but the induction of STAT1 and STAT2 by exogenous IFN $\alpha$ was less robust than that of IFITM1. Interestingly, p-STAT2 (Tyr690) was induced significantly more in SUM149 than in SUM190 cells $1 \mathrm{~h}$ after treatment with IFN $\alpha$ and faded after $5 \mathrm{~h}$. The higher STAT2 phosphorylation in SUM149 cells further supports the critical role it plays in IFITM1 overexpression and partly explains the differences in IFITM1 expression in the IBC cell lines. Additionally, immunofluorescence data (Fig. 8b) showed that exogenous addition of IFN $\alpha$ increased IFITM1 protein expression in both IBC cell lines. Overall, these results show that type I IFN signaling is constitutively enhanced in SUM149 cells; however, these cells are still responsive to exogenous IFN $\alpha$.

\section{Discussion}

IBC is a rare and highly aggressive subtype of breast cancer that is not well characterized at the molecular level. In this study, we report a novel role for the ISG IFITM1 in promoting the aggressive phenotype of SUM149 IBC cells. In particular, we show that IFITM1 was constitutively overexpressed at the mRNA and protein levels in triple- 


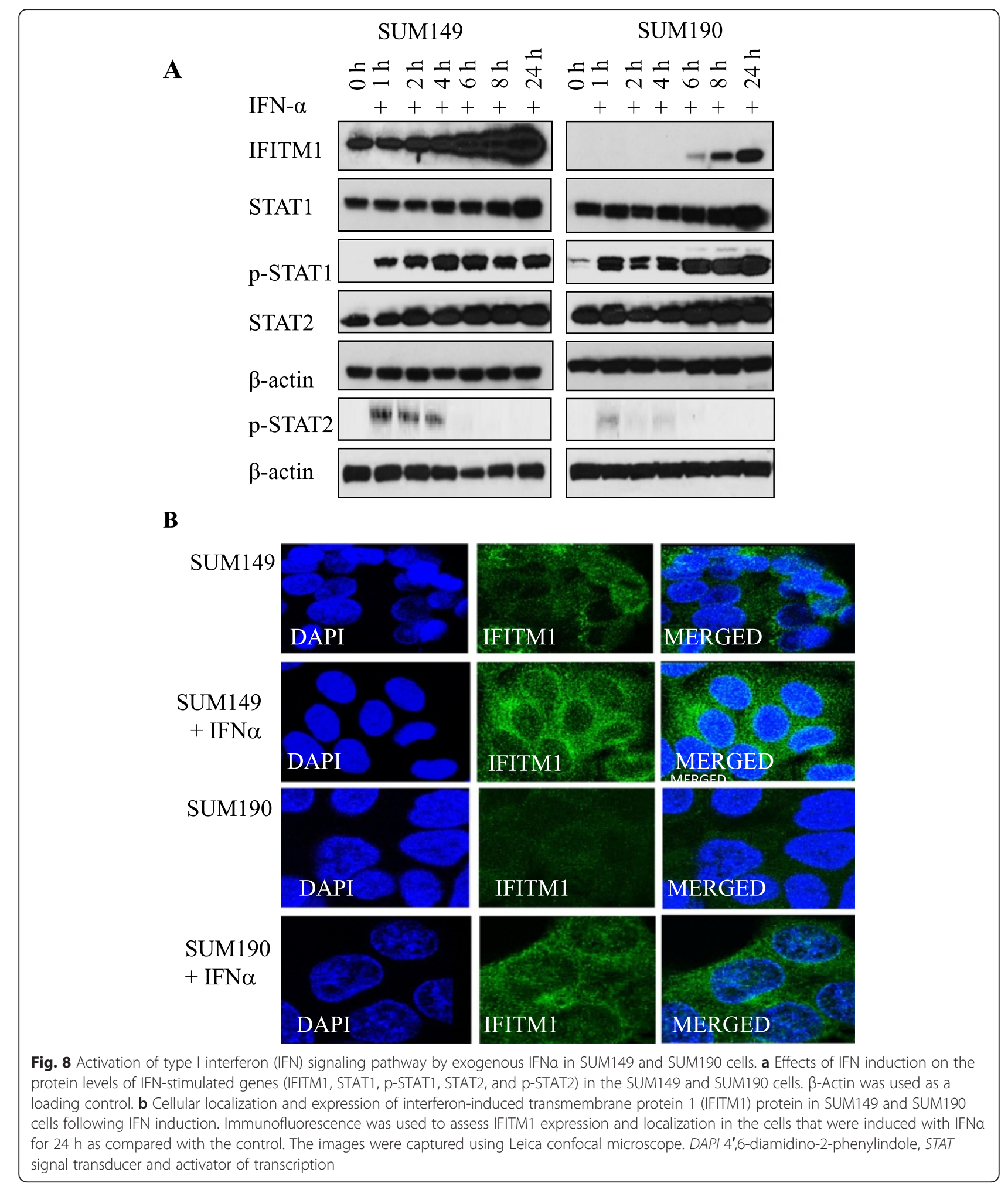

negative SUM149 cells but was not expressed in HER2amplified SUM190 or MDA-IBC-3 IBC cells. We also found that IFITM1 overexpression promoted-whereas its knockdown inhibited-proliferation, migration/invasion, and tumorigenicity in vitro. Furthermore, we demonstrate that SUM149 cells expressed and secreted elevated levels of type I IFN $\alpha$ and that blockade of IFN $\alpha$ signaling using a neutralizing antibody against its receptor, IFNAR1/2, or 
knockdown of STAT2, suppressed IFITM1 expression in SUM149 cells. Loss of IFITM1 expression dramatically reduced the ability of these cells to proliferate, migrate, invade, and form colonies in soft agar. We should note that differential regulation of IFN response genes has been observed in many human malignancies, including leukemia [21], ovarian cancer [23], gastric cancer [14], lung cancer [24], colon cancer [25], and breast cancer [26] and that high expression of ISGs is associated with poor clinical outcome [14]. However, to our knowledge, this study is the first to highlight a critical role for the IFN $\alpha$ signaling pathway and the IFN response gene IFITM1 in enhancing the aggressive phenotype of triple-negative SUM149 cells. The fact that IFITM1 was highly expressed in SUM149 cells, which are triple-negative, but was not expressed in HER2-amplified SUM190 and MDA-IBC-3 cells suggests that it might be a unique molecular marker of TNIBC and that it could be a potential therapeutic target in patients with TNIBC. Approximately $60 \%$ of IBCs are basal-like or triple-negative, as characterized by the ER-, $\mathrm{PR}-$, and human epidermal growth factor receptor 2 (HER2)-nonamplified status [27]. Patients with TNBC have a lower overall survival rate [28] and very limited therapeutic options. In contrast, HER2 amplification occurs in approximately $40 \%$ of IBCs $[29,30]$, and IBC patients with HER2-amplified tumors have been shown to respond favorably to anti-HER2 therapies [31].

Over the past 3 decades, IFNs $(\alpha, \beta, \gamma)$ have established a reputation for being immunologic guardians against disease and as promising antitumor agents [32-35]; however, recent evidence suggests that IFNs may also promote tumor progression. Indeed, it has been reported that breast cancer patients whose tumors express high IFN response genes are 1.7 times more likely to develop metastasis and to die as a result of the disease as compared with patients whose tumors express low levels of the IFN response gene signature [36]. Furthermore, increased expression of a subset of ISGs, including IFITM1, EIF2AK2, STAT1, and IFI27, has been reported in several types of cancers, and these ISGs have been shown to promote tumor growth and resistance to chemotherapy and radiotherapy [11, 37, 38]. Consistent with these reports, our present study revealed constitutive activation of the IFN $\alpha$ signaling pathway in IBC cells, which was strongly associated with IFITM1 overexpression. Notably, blockade of IFN $\alpha$ signaling using a neutralizing antibody against the type I IFN receptor, IFNAR1/2, completely suppressed IFITM1 expression, and it markedly reduced the tumorigenic potential of SUM149 cells in vitro. While the mechanism by which IFITM1 overexpression enhances the aggressiveness of SUM149 cells is not known, we should note that Ras homolog gene family member C GTPase (RhoC-GTPase) is overexpressed in $90 \%$ of IBC tumors as compared with
$38 \%$ of the stage-matched non-IBC tumors and that in SUM149 cells overexpression of RhoC-GTPase is associated with loss of WNT1 inducible signaling pathway 3 (WISP3). Conversely, restoration of WISP3 downregulates RhoC-GTPase and inhibits the invasive potential of SUM149 cells [39]. Indeed, RhoC-GTPase is found to play an essential role in the metastatic behavior of IBC by increasing all aspects of metastatic process, such as cellular motility and invasion, cytoskeletal assembly, and cell adhesion. RhoC-GTPase controls the cytoskeletal reorganization by inducing actin stress fiber and focal adhesion contact formation [40, 41]. While the potential interaction between IFITM1 and RhoC-GTPase was not directly assessed in our study, it has been reported that Rho-GTPases can interact with caveolin 1 (CAV-1) in cancer cells [42]. Notably, IFITM1 has recently been shown to interact with CAV-1 in colorectal cancer cells, and this interaction impacts the ability of colorectal cancer cells to migrate and invade [43]. Additionally, IFITM1 has also been shown to enhance migration and invasion in head and neck cancer cells through activation of matrix metalloproteinase 12 (MMP12) and MMP13, key enzymes involved in the degradation of the basement membrane that allows cells to infiltrate into adjacent tissues [15].

IFN $\alpha$ and IFN $\beta$ are produced by many cell types, including plasmacytoid dendritic cells, lymphocytes, macrophages, and fibroblasts; however, there is evidence that IFNs can also be produced by tumor cells themselves [44-46]. Elevated levels of IFN have been reported in cancer cells as compared with normal primary cells or normal tissues [18, 47, 48]. Furthermore, increased expression of some IFN-induced genes has been shown to be higher in metastatic cancer cells than in nonmetastatic cells [49]. Our data suggest that IFN $\alpha$ levels are significantly elevated in IBC cells as compared with nonIBC cells and that blockade of IFN signaling in these cells markedly reduces IFITM1 expression. It is critical to note that IRF3 and IRF7 are the key regulators of type I IFN production and thus play a central role in innate immunity [50]. IRF7 regulates the transcription of IFNa/ $\beta$ genes and ISGs by binding to an ISRE in their promoters via the virus-activated, myeloid differentiation primary response gene 88 (MyD88)-independent pathway and the Toll-like receptor-activated, MyD88dependent pathway. Notably, we found that IRF7 was markedly elevated ( $>2.5$-fold) at the mRNA and protein levels in SUM149 cells compared with SUM190 cells (data not shown) and that knockdown of IRF7 reduced IFN $\alpha$ level and blocked its signaling through IFNAR1/2 (Fig. 4a). Furthermore, we found that suppression of IFN $\alpha$ and IRF7 dramatically reduced IFITM1 expression in SUM149 cells (Fig. 4b), thus confirming the importance of the IFN $\alpha$ signaling pathway in driving IFITM1 expression in these cells. We should note that while 
endogenous IFN $\alpha$ was elevated in the IBC cells, exogenous addition of IFN $\alpha$ was still able to induce IFITM1, STAT1, and STAT2 in these cells; however, the further induction of these ISGs in SUM149 cells did not alter the growth or aggressive phenotype of these cells.

One of the most prominent findings of our study was the identification of STAT2 as the critical regulator of IFITM1 expression in SUM149 cells. The role of STAT2 in canonical JAK-STAT signaling as a part of ISGF3 complex is well documented; however, there is strong evidence that STAT2 can also homodimerize and combine with IRF9 to form an ISGF3-like complex [51] that translocates to the nucleus. Once in the nucleus, STAT2 recruits BRG1 to the complex, which then binds to the ISRE or GAS sequence of IFITM1 promoter and induces its transcription through noncanonical IFN signaling. It has been reported that STAT2 complexes, without STAT1, are capable of inducing a subset of ISGs without the formation of ISGF3 [52, 53]. For instance, STAT2 was reported to mediate STAT1-independent protection against dengue virus infection in mice that were deficient in STAT1 through the formation of non-ISGF3 complexes that involved STAT2 homodimers, and did not require STAT1 [54]. Additionally, Brierley et al. [52, 55] reported that STAT2 was critical for induction of GASregulated target genes, which was independent of ISGF3. Our study shows that knockdown of STAT2, but not STAT1, completely reduced IFITM1 expression and promoter activity in SUM149 cells. We also found that knockdown of BRG1, the chromatin remodeling protein, also completely suppressed IFITM1 expression in SUM149 cells. BRG1 is the ATP subunit of the chromatin remodeling complex BAF, and studies have shown that STAT2 and BRG1 interact to induce the expression of certain ISGs, including IFITM1, through noncanonical IFN signaling $[56,57]$. There is also evidence that the recruitment of BAF to the IFITM1 promoter is mediated in part by the interaction of BRG1 with STAT2 [58-60]. In our working model shown in Fig. 9, we propose that overexpression of IFITM1 in SUM149 cells is driven by increased expression of IFN $\alpha$, which activates the noncanonical type I IFN signaling pathway where STAT2 homodimers recruit BRG1 to remodel the promoter and expose ISRE, GAS, and IRF consensus sequences for the binding of transcription factors. This model is supported by a study conducted by Blaszczyk et al. [51], which showed that IFN $\alpha$ induction leads to formation of both ISGF3 and STAT2/IRF9 complexes and that the induction of ISGs due to ISGF3 was rapid and transient, while that due to STAT2/IRF9 was slow and prolonged, leading to the expression of ISGs long after the initial induction had ended. Whereas other ISGs have either the ISRE or the GAS sequences, the IFITM1 promoter region has both the ISRE and GAS sequences as well as IRF sequences (Additional file 3: Figure S3).

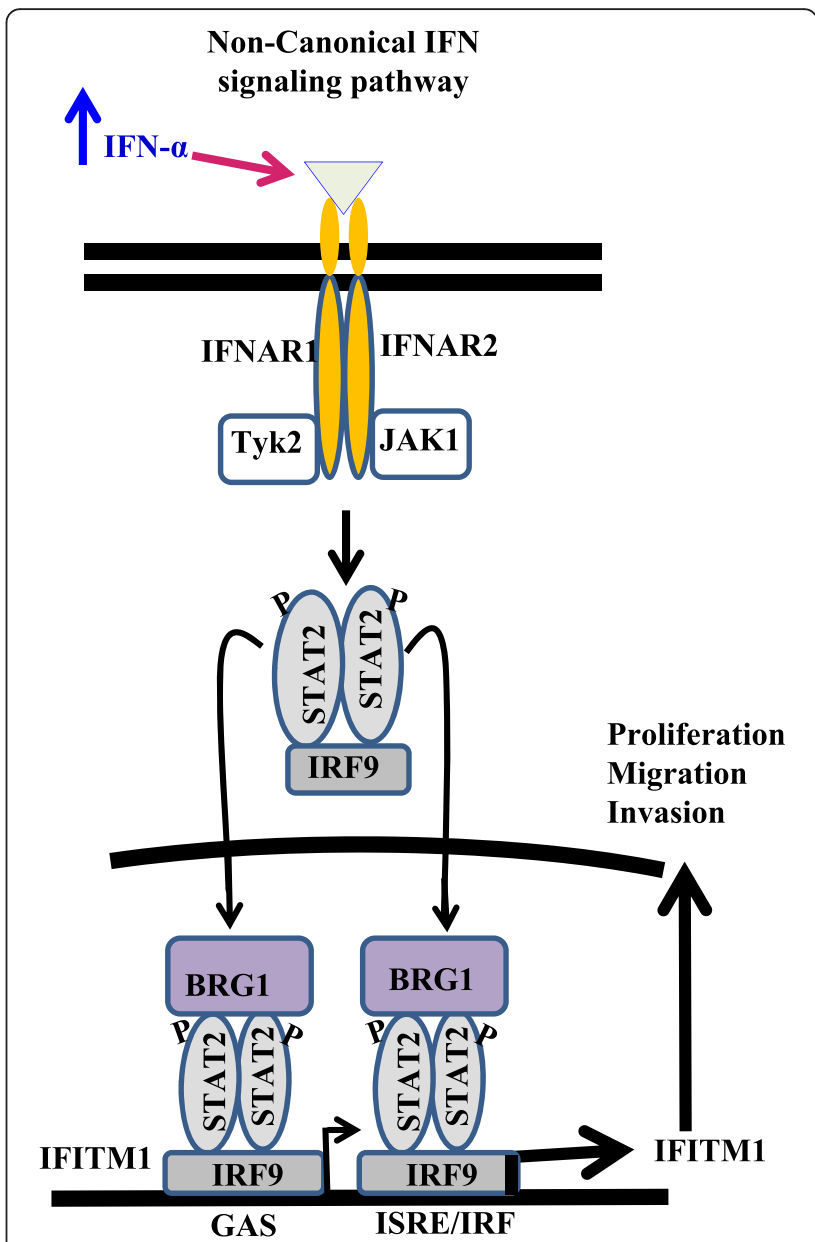

Fig. 9 Schematic diagram depicting the proposed signaling pathway involved in interferon-induced transmembrane protein 1 (IFITM1) upregulation in SUM149 cells. IFITM1 is one of the interferonstimulated genes (ISGS) that are induced through the canonical Janus kinase/signal transducer and activator of transcription (JAK-STAT) pathway due to increased expression of interferon a (IFNa). The binding of IFNa to its receptor interferon (alpha, beta and omega) receptor (IFNAR1/2) leads to the induction of the canonical JAK-STAT pathway, which involves phosphorylation of STAT1, STAT2, and the formation of the complex interferon-stimulated gene factor 3 (ISGF3), ultimately inducing many ISGs, including IFITM1. In the nucleus, ISGF3 recruits chromatin remodeling complex brahma-related gene 1 (BRG1) via STAT2 to remodel the promoter and expose interferon-stimulated response element (ISRE)/interferon gamma-activated site (GAS) for transcription factor binding. Alternatively, STAT2 can homodimerize upon phosphorylation, and bind interferon regulatory factor 9 (IRF9) to form a non-ISGF3 complex that is capable of binding the GAS or ISRE/ IRF sequences at the promoter region of a subset of ISGs and induce their transcription without the participation of STAT1 in a noncanonical interferon signaling pathway. The presence of both GAS and ISRE/RF consensus sequences at the IFITM1 promoter suggests that its transcription can be induced by both canonical and noncanonical signaling pathways, resulting in its overexpression in SUM149 cells

Additionally, STAT2 knockdown in SUM149 cells yielded results similar to those for IFITM1 knockdown; however, STAT1 knockdown had little or no effect on the growth or 
invasive potential of these cells, thus supporting a critical role for STAT2-BRG1 crosstalk in regulating IFITM1 expression in these cells.

\section{Conclusions}

Our present study reveals a critical role for the IFNa signaling pathway and IFITM1 overexpression in promoting the aggressive phenotype of the TNIBC cell line SUM149. The fact that IFITM1 is not expressed in the HER2-amplified IBC cell lines SUM190 and MDA-IBC3 suggests that IFITM1 overexpression might be a unique marker of aggressiveness in TNIBC. However, further studies using additional TNIBC cell lines and IBC tumors are needed to fully assess the prognostic and therapeutic potential of IFITM1 expression in IBC.

\section{Additional files}

Additional file 1: Figure S1. Effects of IFITM1 knockdown on cell cycle and cell-cycle proteins in SUM149 cells. (PPT $212 \mathrm{~kb}$ )

Additional file 2: Figure S2. STAT1 and STAT2 knockdown in SUM149 using three different siRNAs. (PPT $185 \mathrm{~kb}$ )

Additional file 3: Figure S3. IFITM1 promoter sequence. (PPT 78 kb)

\section{Abbreviations}

ATP: adenosine triphosphate; BAF: brahma-associated factor; BRG1: brahmarelated gene 1; CAV-1: caveolin 1; CDNA: complementary DNA;

CGH: comparative genomic hybridization; DAPI: 4,6-diamidino-2phenylindole; ELISA: enzyme-linked immunosorbent assay; ER: estrogen receptor; FBS: fetal bovine serum; GAS: interferon gamma-activated site; HER2: human epidermal growth factor receptor 2; IBC: inflammatory breast cancer; IFI27: interferon-inducible protein 27; IFIT1: interferon-induced protein with tetratricopeptide repeats 1; IFITM1: interferon-induced transmembrane protein 1; IFN: interferon; IFNAR: interferon (alpha, beta and omega) receptor; IgG: immunoglobulin G; IRF: interferon regulatory factor; ISG: interferonstimulated gene; ISGF3: interferon-stimulated gene factor 3; ISRE: interferonstimulated response element; JAK: Janus kinase; MMP: matrix metalloproteinase; mRNA: messenger RNA; MTT: 3-(4,5-dimethylthiazol-2-yl)-2,5-diphenyltetrazolium bromide; MyD88: myeloid differentiation primary response gene 88; PBS: phosphate-buffered saline; PLSCR1: phospholipid scramblase 1; PUM1: Pumilio RNA-binding family member 1; RhoC-GTPase: Ras homolog gene family, member C GTPase; RIPA: radioimmunoprecipitation assay; RLU: Relative Light Units;

RT-PCR: real-time polymerase chain reaction; SD: standard deviation; SDS: sodium dodecyl sulfate; shRNA: short hairpin RNA; siCon: scrambled control RNA; silFN: small interfering interferon; siRNA: small interfering RNA; STAT: signal transducer and activator of transcription; TBS-T: Tris-buffered saline and Tween 20; TNIBC: triple-negative inflammatory breast cancer; WISP3: WNT1 inducible signaling pathway 3.

\section{Competing interests}

The authors declare that they have no competing interests.

\section{Authors' contributions}

JLW conceived the study, participated in the research design and implementation of the study, analyzed and interpreted the data, and drafted the manuscript. JO performed the experiments, analyzed the data, and drafted and revised the manuscript. HJC performed some of the experiments, analyzed some of the data, and assisted in drafting the manuscript. AL performed and analyzed the ELISA data and revised the manuscript. MC provided critical reagents for the study and also revised the manuscript. All authors read and approved the final manuscript.

\section{Authors' information}

JWO, PhD, is a postdoctoral fellow in the Department of Cancer Biology, University of Kansas Medical Center. HJC, PhD, is a postdoctoral fellow in the Department of Cancer Biology, University of Kansas Medical Center. AL, MD, $\mathrm{PhD}$, candidate in the Department of Molecular and Integrative Physiology, University of Kansas Medical Center. MC, MD, is a professor, in the Division of Hematology-Oncology, Department of Medicine, Northwestern University Feinberg School of Medicine. JLW, PhD, is an assistant professor in the Department of Cancer Biology, University of Kansas Medical Center.

\section{Acknowledgments}

This work was supported by grants from the Department of Defense (W81XWH-12-1-0139; to JLW, HJC, and AL) and the National Cancer Institute (K01CA120051; to JLW), and by start-up funds from the University of Kansas Medical Center (to JLW, HJC, JO, and AL). We thank the Flow Cytometry Core Facility, which is sponsored in part by Centers of Biomedical Research Excellence (COBRE) grant P30 GM103326 from the National Institute of General Medical Sciences of the National Institutes of Health, and the University of Kansas Medical Center Imaging Core for the use of their facilities and equipment. Plasmid DNA constructs [pGL3-Basic, pGL3-IFITM1 (-750/-1), and pGL3-IFITM1 $(-200 /-1)]$ were kindly provided by Dr. Yeon-Su Lee (National Cancer Center, South Korea).

\section{Author details}

'Department of Cancer Biology, University of Kansas Medical Center, Kansas City, KS, USA. ²Department of Molecular and Integrative Physiology, University of Kansas Medical Center, Kansas City, KS, USA. ${ }^{3}$ Department of Medical Oncology, Northwestern University, Chicago, IL, USA.

Received: 1 June 2015 Accepted: 3 February 2016

Published online: 20 February 2016

\section{References}

1. Fouad TM, Kogawa T, Liu DD, Shen Y, Masuda H, El-Zein R, et al. Overall survival differences between patients with inflammatory and noninflammatory breast cancer presenting with distant metastasis at diagnosis. Breast Cancer Res Treat. 2015;152(2):407-16.

2. Robertson FM, Bondy M, Yang W, Yamauchi H, Wiggins S, Kamrudin S, et al. Inflammatory breast cancer: the disease, the biology, the treatment. CA Cancer J Clin. 2010;60(6):351-75.

3. Bertucci F, Ueno NT, Finetti P, Vermeulen P, Lucci A, Robertson FM, et al. Gene expression profiles of inflammatory breast cancer: correlation with response to neoadjuvant chemotherapy and metastasis-free survival. Ann Oncol. 2014;25(2):358-65.

4. Woodward WA, Krishnamurthy S, Yamauchi H, El-Zein R, Ogura D, Kitadai E, et al. Genomic and expression analysis of microdissected inflammatory breast cancer. Breast Cancer Res Treat. 2013;138(3):761-72.

5. Cristofanilli M, Valero V, Buzdar AU, Kau SW, Broglio KR, Gonzalez-Angulo AM, et al. Inflammatory breast cancer (IBC) and patterns of recurrence: understanding the biology of a unique disease. Cancer. 2007;110(7):1436-44.

6. Silvera D, Arju R, Darvishian F, Levine PH, Zolfaghari L, Goldberg J, et al. Essential role for elF4Gl overexpression in the pathogenesis of inflammatory breast cancer. Nat Cell Biol. 2009;11(7):903-8.

7. Bertucci F, Finetti $P$, Vermeulen $P$, Van Dam P, Dirix L, Birnbaum D, et al. Genomic profiling of inflammatory breast cancer: a review. Breast. 2014;23(5):538-45

8. Sarasin-Filipowicz M, Wang X, Yan M, Duong FH, Poli V, Hilton DJ, et al. Alpha interferon induces long-lasting refractoriness of JAK-STAT signaling in the mouse liver through induction of USP18/UBP43. Mol Cell Biol. 2009;29(17):4841-51.

9. Ivashkiv LB, Donlin LT. Regulation of type I interferon responses. Nat Rev Immunol. 2014;14(1):36-49.

10. Critchley-Thorne RJ, Simons DL, Yan N, Miyahira AK, Dirbas FM, Johnson DL, et al. Impaired interferon signaling is a common immune defect in human cancer. Proc Natl Acad Sci U S A. 2009;106(22):9010-5.

11. Khodarev NN, Roizman B, Weichselbaum RR. Molecular pathways: interferon/Stat1 pathway: role in the tumor resistance to genotoxic stress and aggressive growth. Clin Cancer Res. 2012;18(11):3015-21. 
12. Lee HJ, Zhuang G, Cao Y, Du P, Kim HJ, Settleman J. Drug resistance via feedback activation of Stat3 in oncogene-addicted cancer cells. Cancer Cell. 2014;26(2):207-21.

13. Calo V, Migliavacca M, Bazan V, Macaluso M, Buscemi M, Gebbia N, et al. STAT proteins: from normal control of cellular events to tumorigenesis. J Cell Physiol. 2003;197(2):157-68.

14. Lee J, Goh SH, Song N, Hwang JA, Nam S, Choi IJ, et al. Overexpression of IFITM1 has clinicopathologic effects on gastric cancer and is regulated by an epigenetic mechanism. Am J Pathol. 2012;181(1):43-52.

15. He JD, Luo HL, Li J, Feng WT, Chen LB. Influences of the interferon induced transmembrane protein 1 on the proliferation, invasion, and metastasis of the colorectal cancer SW480 cell lines. Chin Med J (Engl). 2012;125(3):517-22

16. Yang $G, X u Y$, Chen $X, H u$ G. IFITM1 plays an essential role in the antiproliferative action of interferon- . Oncogene. 2007:26(4):594-603.

17. Johnson MC, Sangrador-Vegas A, Smith TJ, Cairns MT. Cloning and characterization of two genes encoding rainbow trout homologues of the IFITM protein family. Vet Immunol Immunopathol. 2006;110(3-4):357-62.

18. Hatano H, Kudo Y, Ogawa I, Tsunematsu T, Kikuchi A, Abiko Y, et al. IFN-induced transmembrane protein 1 promotes invasion at early stage of head and neck cancer progression. Clin Cancer Res. 2008;14(19):6097-105.

19. Yu F, Ng SS, Chow BK, Sze J, Lu G, Poon WS, et al. Knockdown of interferoninduced transmembrane protein 1 (IFITM1) inhibits proliferation, migration, and invasion of glioma cells. J Neurooncol. 2011;103(2):187-95.

20. Pan Z, Chen S, Pan X, Wang Z, Han H, Zheng W, et al. Differential gene expression identified in Uigur women cervical squamous cell carcinoma by suppression subtractive hybridization. Neoplasma. 2010;57(2):123-8.

21. Gomes AQ, Correia DV, Grosso AR, Lança T, Ferreira C, Lacerda JF, et al. Identification of a panel of ten cell surface protein antigens associated with immunotargeting of leukemias and lymphomas by peripheral blood $T$ cells. Haematologica. 2010;95(8):1397-404.

22. Debeb BG, Cohen EN, Boley K, Freiter EM, Li L, Robertson FM, et al. Pre-clinical studies of Notch signaling inhibitor RO4929097 in inflammatory breast cancer cells. Breast Cancer Res Treat. 2012;134(2):495-510.

23. Johnatty SE, Beesley J, Chen X, Macgregor S, Duffy DL, Spurdle AB, et al. Evaluation of candidate stromal epithelial cross-talk genes identifies association between risk of serous ovarian cancer and TERT, a cancer susceptibility hot-spot. PLoS Genet. 2010;6(7):e1001016.

24. Luszczek W, Cheriyath V, Mekhail TM, Borden EC. Combinations of DNA methyltransferase and histone deacetylase inhibitors induce DNA damage in small cell lung cancer cells: correlation of resistance with IFN-stimulated gene expression. Mol Cancer Ther. 2010;9(8):2309-21.

25. Gongora C, Candeil L, Vezzio N, Copois V, Denis V, Breil C, et al. Altered expression of cell proliferation-related and interferon-stimulated genes in colon cancer cells resistant to SN38. Cancer Biol Ther. 2008;7(6):822-32.

26. Choi HJ, Lui A, Ogony J, Jan R, Sims PJ, Lewis-Wambi J. Targeting interferon response genes sensitizes aromatase inhibitor resistant breast cancer cells to estrogen-induced cell death. Breast Cancer Res. 2015;17:6.

27. Van Laere S, Van der Auwera I, Van den Eynden G, Van Hummelen P, van Dam P, Van Marck E, et al. Distinct molecular phenotype of inflammatory breast cancer compared to non-inflammatory breast cancer using Affymetrix-based genome-wide gene-expression analysis. $\mathrm{Br} J$ Cancer. 2007:97(8):1165-74.

28. Li J, Gonzalez-Angulo AM, Allen PK, Yu TK, Woodward WA, Ueno NT, et al. Triple-negative subtype predicts poor overall survival and high locoregional relapse in inflammatory breast cancer. Oncologist. 2011;16(12):1675-83.

29. Cabioglu N, Gong Y, Islam R, Broglio KR, Sneige N, Sahin A, et al. Expression of growth factor and chemokine receptors: new insights in the biology of inflammatory breast cancer. Ann Oncol. 2007;18(6):1021-9.

30. Masuda H, Zhang D, Bartholomeusz C, Doihara H, Hortobagyi GN, Ueno NT. Role of epidermal growth factor receptor in breast cancer. Breast Cancer Res Treat. 2012;136(2):331-45

31. Yamauchi H, Cristofanilli M, Nakamura S, Hortobagyi GN, Ueno NT. Molecular targets for treatment of inflammatory breast cancer. Nat Rev Clin Oncol. 2009:6(7):387-94.

32. Dunn GP, Old $\sqcup$, Schreiber RD. The immunobiology of cancer immunosurveillance and immunoediting. Immunity. 2004;21(2):137-48.

33. Schreiber RD, Old LJ, Smyth MJ. Cancer immunoediting: integrating immunity's roles in cancer suppression and promotion. Science (New York, NY). 2011;331(6024):1565-70.
34. Ferrantini M, Capone I, Marincola FM, Parmiani G, Belardelli F. International meeting Immunotherapy of Cancer: Challenges and Needs. Cancer Immunol Immunother. 2007;56(4):581-5.

35. Moschos S, Kirkwood JM. Present role and future potential of type I interferons in adjuvant therapy of high-risk operable melanoma. Cytokine Growth Factor Rev. 2007;18(5-6):451-8.

36. Buess M, Nuyten DS, Hastie T, Nielsen T, Pesich R, Brown PO. Characterization of heterotypic interaction effects in vitro to deconvolute global gene expression profiles in cancer. Genome Biol. 2007:8(9):R191.

37. Cheon H, Borden EC, Stark GR. Interferons and their stimulated genes in the tumor microenvironment. Semin Oncol. 2014;41(2):156-73.

38. Khodarev NN, Roach P, Pitroda SP, Golden DW, Bhayani M, Shao MY, et al. STAT1 pathway mediates amplification of metastatic potential and resistance to therapy. PLoS One. 2009:4(6):e5821.

39. Kleer CG, Zhang Y, Pan Q, Gallagher G, Wu M, Wu ZF, et al. WISP3 and RhoC guanosine triphosphatase cooperate in the development of inflammatory breast cancer. Breast Cancer Res. 2004;6(1):R110-5.

40. van Golen KL, Bao L, DiVito MM, Wu Z, Prendergast GC, Merajver SD. Reversion of RhoC GTPase-induced inflammatory breast cancer phenotype by treatment with a farnesyl transferase inhibitor. Mol Cancer Ther. 2002;1 (8):575-83.

41. van Golen KL, Wu ZF, Qiao XT, Bao L, Merajver SD. RhoC GTPase overexpression modulates induction of angiogenic factors in breast cells. Neoplasia (New York, NY). 2000;2(5):418-25.

42. Arpaia E, Blaser H, Quintela-Fandino M, Duncan G, Leong HS, Ablack A, et al. The interaction between caveolin-1 and Rho-GTPases promotes metastasis by controlling the expression of alpha5-integrin and the activation of Src. Ras and Erk Oncogene. 2012:31(7):884-96.

43. Yu F, Xie D, Ng SS, Lum CT, Cai MY, Cheung WK, et al. IFITM1 promotes the metastasis of human colorectal cancer via CAV-1. Cancer Lett. 2015:368(1):135-43.

44. Fuertes MB, Woo SR, Burnett B, Fu YX, Gajewski TF. Type I interferon response and innate immune sensing of cancer. Trends Immunol. 2013;34(2):67-73.

45. Gajewski TF, Schreiber H, Fu YX. Innate and adaptive immune cells in the tumor microenvironment. Nat Immunol. 2013;14(10):1014-22.

46. Yang X, Zhang X, Fu ML, Weichselbaum RR, Gajewski TF, Guo Y, et al. Targeting the tumor microenvironment with interferon-beta bridges innate and adaptive immune responses. Cancer Cell. 2014;25(1):37-48.

47. Perou CM, Jeffrey SS, van de Rijn M, Rees CA, Eisen MB, Ross DT, et al. Distinctive gene expression patterns in human mammary epithelial cells and breast cancers. Proc Natl Acad Sci U S A. 1999;96(16):9212-7.

48. Suomela S, Cao L, Bowcock A, Saarialho-Kere U. Interferon alpha-inducible protein 27 (IFI27) is upregulated in psoriatic skin and certain epithelial cancers. J Invest Dermatol. 2004;122(3):717-21.

49. Cai D, Cao J, Li Z, Zheng X, Yao Y, Li W, et al. Up-regulation of bone marrow stromal protein 2 (BST2) in breast cancer with bone metastasis. BMC Cancer. 2009;9:102.

50. Ning S, Pagano JS, Barber GN. IRF7: activation, regulation, modification and function. Genes Immun. 2011;12(6):399-414

51. Blaszczyk K, Olejnik A, Nowicka H, Ozgyin L, Chen YL, Chmielewski S, et al. STAT2/IRF9 directs a prolonged ISGF3-like transcriptional response and antiviral activity in the absence of STAT1. Biochem J. 2015;466(3):511-24

52. Brierley MM, Marchington $\mathrm{KL}$, Jurisica I, Fish EN. Identification of GAS-dependent interferon-sensitive target genes whose transcription is STAT2-dependent but ISGF3-independent. FEBS J. 2006;273(7):1569-81.

53. Steen HC, Gamero AM. STAT2 phosphorylation and signaling. JAKSTAT. 2013;2(4):e25790.

54. Perry ST, Buck MD, Lada SM, Schindler C, Shresta S. STAT2 mediates innate immunity to Dengue virus in the absence of STAT1 via the type I interferon receptor. PLoS Pathog. 2011;7(2):e1001297.

55. Brierley MM, Fish EN. Functional relevance of the conserved DNA-binding domain of STAT2. J Biol Chem. 2005;280(13):13029-36.

56. Huang M, Qian F, Hu Y, Ang C, Li Z, Wen Z. Chromatin-remodelling factor BRG1 selectively activates a subset of interferon-alpha-inducible genes. Nat Cell Biol. 2002:4(10):774-81.

57. Cui K, Tailor P, Liu H, Chen X, Ozato K, Zhao K. The chromatin-remodeling BAF complex mediates cellular antiviral activities by promoter priming. Mol Cell Biol. 2004;24(10):4476-86. 
58. Yan Z, Cui K, Murray DM, Ling C, Xue Y, Gerstein A, et al. PBAF chromatinremodeling complex requires a novel specificity subunit, BAF200, to regulate expression of selective interferon-responsive genes. Genes Dev. 2005;19(14):1662-7.

59. Ni Z, Karaskov E, Yu T, Callaghan SM, Der S, Park DS, et al. Apical role for BRG1 in cytokine-induced promoter assembly. Proc Natl Acad Sci U S A. 2005;102(41):14611-6.

60. Liu H, Kang H, Liu R, Chen X, Zhao K. Maximal induction of a subset of interferon target genes requires the chromatin-remodeling activity of the BAF complex. Mol Cell Biol. 2002;22(18):6471-9.

Submit your next manuscript to BioMed Central and we will help you at every step:

- We accept pre-submission inquiries

- Our selector tool helps you to find the most relevant journal

- We provide round the clock customer support

- Convenient online submission

- Thorough peer review

- Inclusion in PubMed and all major indexing services

- Maximum visibility for your research

Submit your manuscript at www.biomedcentral.com/submit
Biomed Central 